San Jose State University

SJSU ScholarWorks

Master's Theses

Master's Theses and Graduate Research

1993

\title{
Comparative study on splinting, hand function and pain in thumb carpometacarpal arthritis
}

\author{
Yuriko Wong \\ San Jose State University
}

Follow this and additional works at: https://scholarworks.sjsu.edu/etd_theses

\section{Recommended Citation}

Wong, Yuriko, "Comparative study on splinting, hand function and pain in thumb carpometacarpal arthritis" (1993). Master's Theses. 724.

DOI: https://doi.org/10.31979/etd.mpht-wgk5

https://scholarworks.sjsu.edu/etd_theses/724

This Thesis is brought to you for free and open access by the Master's Theses and Graduate Research at SJSU ScholarWorks. It has been accepted for inclusion in Master's Theses by an authorized administrator of SJSU ScholarWorks. For more information, please contact scholarworks@sjsu.edu. 


\section{INFORMATION TO USERS}

This manuscript has been reproduced from the microfilm master. UMI films the text directly from the original or copy subrnitted. Thus, some thesis and dissertation copies are in typewriter face, while others may be from any type of computer printer.

The quality of this reproduction is dependent upon the quality of the copy submitted. Broken or indistinct print, colored or poor quality illustrations and photographs, print bleedthrough, substandard margins, and improper alignment can adversely affect reproduction.

In the unlikely event that the author did not send UMI a complete manuscript and there are missing pages, these will be noted. Also, if unauthorized copyright material had to be removed, a note will indicate the deletion.

Oversize materials (e.g., maps, drawings, charts) are reproduced by sectioning the original, beginning at the upper left-hand corner and continuing from left to right in equal sections with small overlaps. Each original is also photographed in one exposure and is included in reduced form at the back of the book.

Photographs included in the original manuscript have been reproduced xerographically in this copy. Higher quality $6 "$ " 9 9" black and white photographic prints are available for any photographs or illustrations appearing in this copy for an additional charge. Contact UMI directly to order.

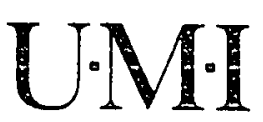

University Microfilms International

A Bell \& Howell information Company

$3 n 0$ North Zeeb Road. Ann Arbor. MI 48106-1346 USA

$313 / 761-4700 \quad 800 / 521.0600$ 

Order Number 1356507

Comparative study on splinting, hand function and pain in thumb carpometacarpal arthritis

\author{
Wong, Yuriko, M.S.
}

San Jose State University, 1993

Copyright @1993 by Wong, Yuriko. All rights reserved.

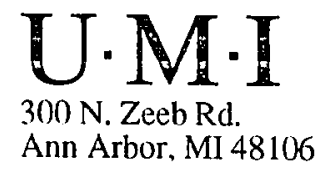


, 
COMPARATIVE STUDY ON SPLINTING, HAND FUNCTION AND PAIN

IN THUMB CARPOMETACARPAL ARTHRITIS

\author{
A Thesis \\ Presented to \\ The Faculty of the Department of Occupational Therapy \\ San Jose State University \\ In Partial Fulfillment \\ of the Requirements for the Degree \\ Master of Science
}

By

Yuriko Wong

December, 1993 
(C) 1993

Yuriko Wong

ALL RIGHTS RESERVED 
APPROVED FOR THE DEPARTMENT OF OCCUPATIONAL THERAPY
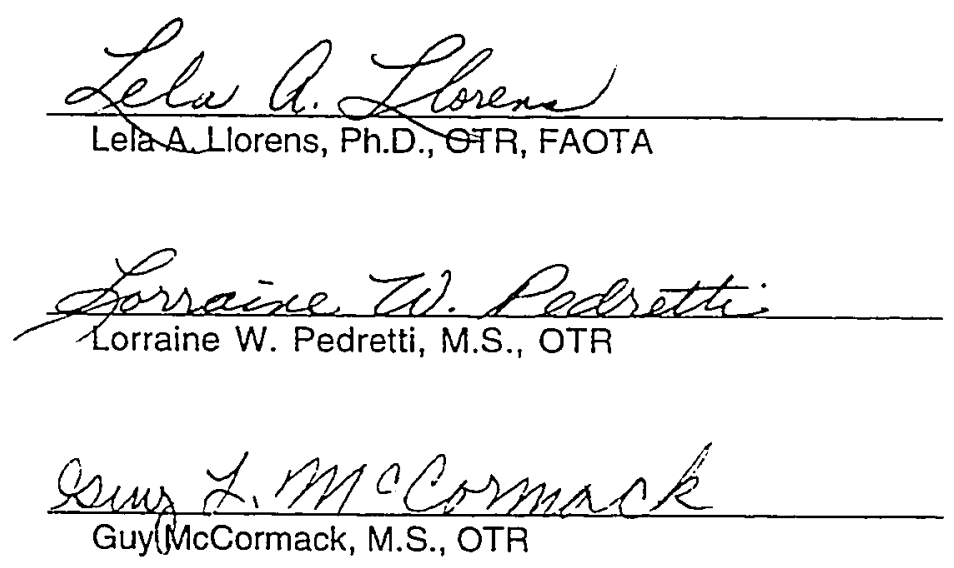

APPROVED FOR THE UNIVERSITY

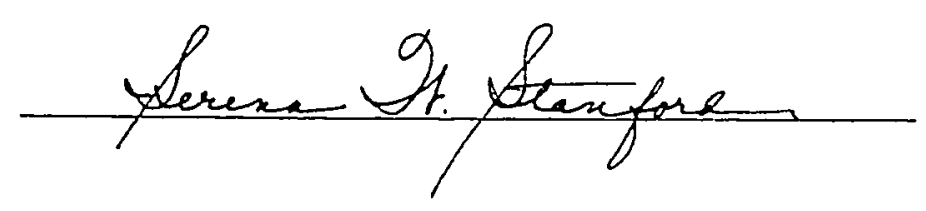


ABSTRACT

COMPARATIVE STUDY ON SPLINTING, HAND FUNCTION AND PAIN

IN THUMB CARPOMETACARPAL ARTHRITIS

by Yuriko Wong

The purpose of the research was to study hand function and perceived pain sensation under conditions of no splint, short splint and long splint with five subjects diagnosed with carpometacarpal arthritis at the Hand Clinic at the Palo Alto Veterans Affairs Medical Center. The subjects were tested on grip, pinch, Jebsen Hand Function Test and functional activities such as turning a key and turning a door knob.

The results of the study indicated that there were no differences in motor function under the three conditions. There were significant changes in the pain scores between the no splint, short splint and long splint. Pain with no splint was greater than both splints, but there was no difference between the short and long splint for pain relief. Further studies are recommended. 


\section{ACKNOWLEDGMENTS}

I would like to thank the faculty at San Jose State University, my family, friends, coworkers, staff, patients, and doctors who were involved with the completion of this research. 1 appreciated the support and encouragement.

Thank you, Dr. Lela Llorens, for your input and guidance in getting me through the thesis process. What a role model you are for the profession! My gratitude to Professor Lorraine Pedretti for your review of my thesis and for the articulation of the theory of Occupational Performance for physical disabilities. Thank you, Professor Guy McCormack for your interest and time for this paper.

I'd like to thank Dr. Vincent Hentz, Chief of Upper Extremity at Stanford University, a wonderful hand surgeon, and instructor in the study of the hand and upper extremity who sparked my interest in hand therapy years ago. Thank you to the VA Hand Clinic doctors, especially Dr. Yim and Dr. Han for such good referrals.

Special thanks to Jim Moses, Ph.D., neuropsychologist, and friend for his time, and patience. I also appreciated your support, and encouragement for my paper.

Thank you to Debbie Kenney, M.S , OTR, Janet Weis, OTR, for the moral support, and assistance in completing this thesis.

A special thank you to Karen Nelson, M.S, OTR, for thesis support and for reminding me that "it is now your turn." 


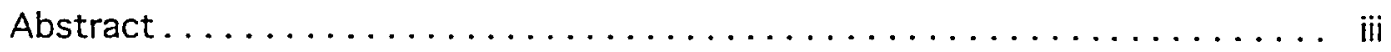

Acknowledgments $\ldots \ldots \ldots \ldots \ldots \ldots \ldots \ldots \ldots \ldots \ldots \ldots$ iv

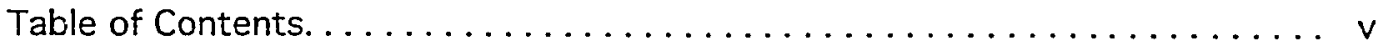

List of Tables $\ldots \ldots \ldots \ldots \ldots \ldots \ldots \ldots \ldots \ldots \ldots \ldots \ldots \ldots$ viii

List of Figures $\ldots \ldots \ldots \ldots \ldots \ldots \ldots \ldots \ldots \ldots \ldots \ldots \ldots \ldots \ldots \ldots \ldots \ldots \ldots$

Chapter 1: INTRODUCTION

Purpose of the Study $\ldots \ldots \ldots \ldots \ldots \ldots \ldots \ldots \ldots \ldots \ldots \ldots$

Statement of the Problem $\ldots \ldots \ldots \ldots \ldots \ldots \ldots \ldots \ldots \ldots \ldots$

Research Questions ......................... 2

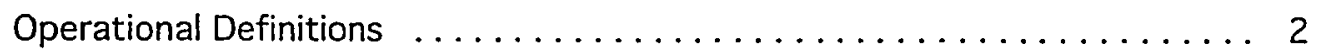

Assumptions . . . . . . . . . . . . . . .

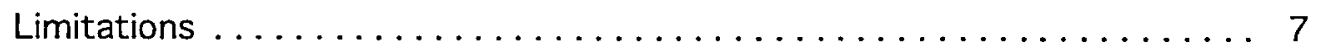

Significance of the Study $\ldots \ldots \ldots \ldots \ldots \ldots \ldots \ldots \ldots$

Chapter 2: LITERATURE REVIEW

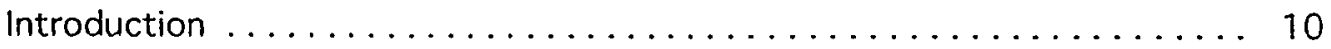

Anatomy and Biomechanics . . . . . . . . . . . 10

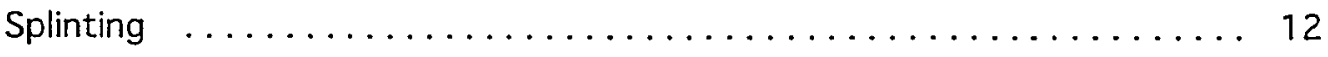

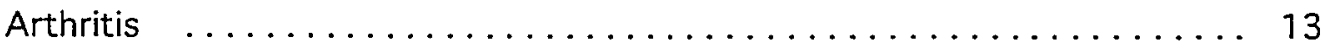

Assessment of Pain. ..................... 14

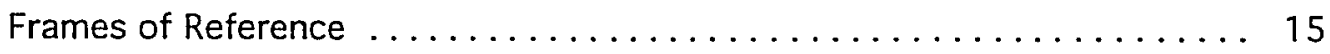

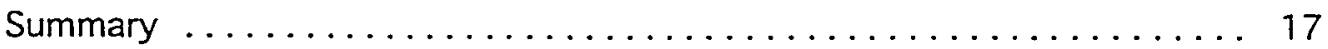

Chapter 3: DESIGN AND METHODOLOGY

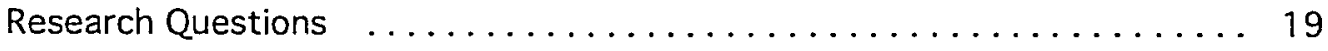


Research Design ........................... 19

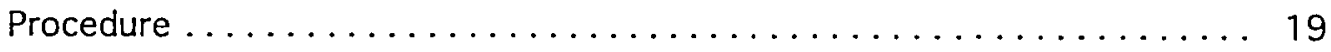

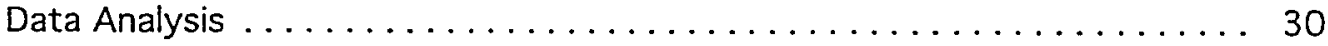

\section{Chapter 4: DATA AND RESULTS}

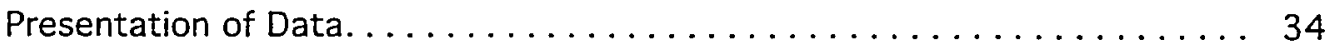

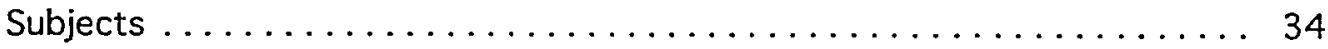

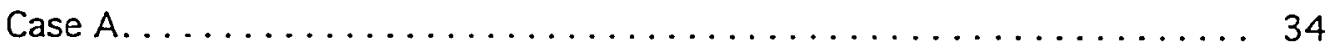

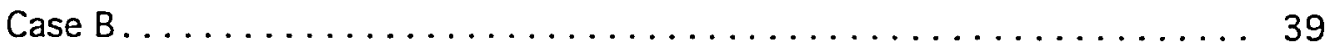

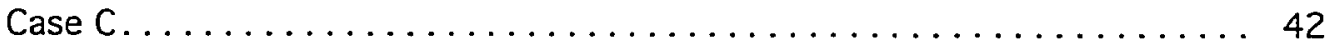

Case D................................. 48

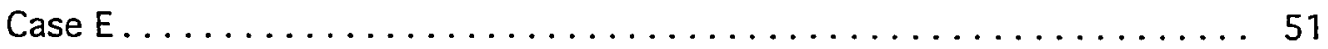

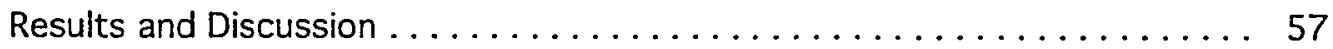

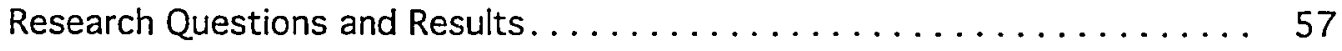

Chapter 5: PROFESSIONAL IMPLICATIONS AND RECOMMENDATIONS

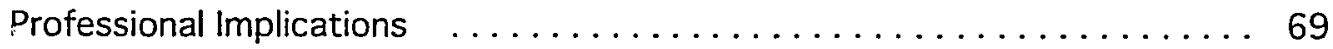

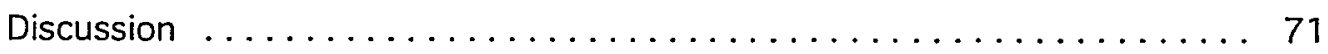

Recommendations....................... 72

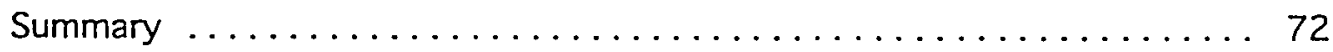

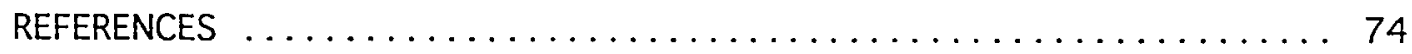

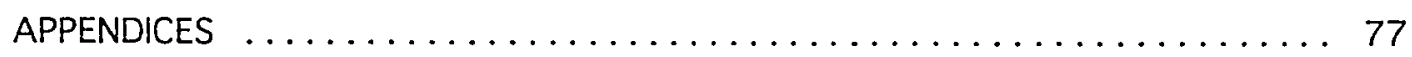

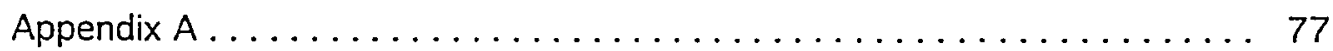

SJSU Human Subject Informed Consent. . . . . . . . . . . . . 78

Appendix B ................................ 80

Carpometacarpal Data Sheet: Case A. . . . . . . . . . . 81

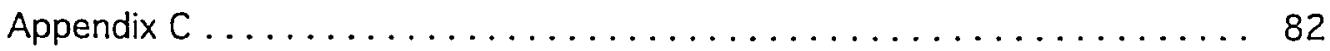

Jebsen Means and Standard Deviation. . . . . . . . . . . . 83 
Appendix D . . . . . . . . . . . . . . . 84

Carpometacarpal Data Sheet: Case B. . . . . . . . . . . . . 85

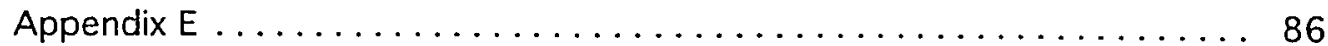

Carpometacarpal Data Sheet: Case C.................. 87

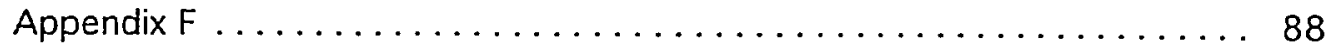

Carpometacarpal Data Sheet: Case D. . . . . . . . . . . . . . . 89

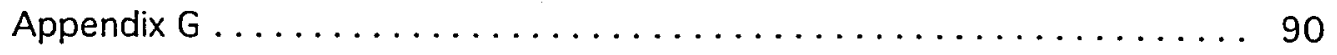

Carpometacarpal Data Sheet: Case E................... 91 


\section{List of Tables}

Table

Page

1. Subject A: Jebsen Hand Function Scores $\ldots \ldots \ldots \ldots \ldots \ldots \ldots \ldots \ldots \ldots$

2. Subject B: Jebsen Hand Function Scores $\ldots \ldots \ldots \ldots \ldots \ldots \ldots \ldots \ldots$

3. Subject C: Jebsen Hand Function Scores $\ldots \ldots \ldots \ldots \ldots \ldots \ldots \ldots \ldots$

4. Subject $D$ : Jebsen Hand Function Scores . . . . . . . . . . . 50

5. Subject E: Jebsen Hand Function Scores $\ldots \ldots \ldots \ldots \ldots \ldots \ldots \ldots \ldots$ 


\section{LIST OF FIGURES}

Figures

Page

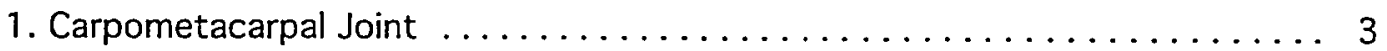

2. Short Hand-Based Thumb Carpometacarpal Splint $\ldots \ldots \ldots \ldots \ldots \ldots$

3. Long Carpometacarpal Splint $\ldots \ldots \ldots \ldots \ldots \ldots \ldots \ldots \ldots \ldots \ldots \ldots \ldots \ldots \ldots \ldots$

4. Jebsen Hand Function Test - Subtest $1 \ldots \ldots \ldots \ldots \ldots \ldots \ldots$

5. Jebsen Hand Function Test - Subtest $2 \ldots \ldots \ldots \ldots \ldots \ldots \ldots \ldots \ldots$

6. Jebsen Hand Function Test - Subtest $3 \ldots \ldots \ldots \ldots \ldots \ldots \ldots$

7. Jebsen Hand Function Test - Subtest $4 \ldots \ldots \ldots \ldots \ldots \ldots \ldots \ldots$

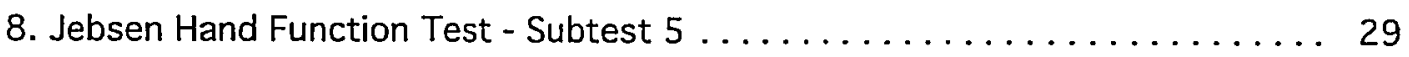

9. Jebsen Hand Function Test - Subtest $6 \& 7 \ldots \ldots \ldots \ldots \ldots \ldots \ldots$

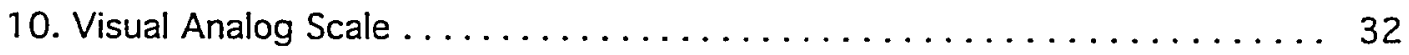

11. Subject A: Pain Score and Activities $\ldots \ldots \ldots \ldots \ldots \ldots \ldots \ldots$

12. Subject A: Grip / Pinch Scores $\ldots \ldots \ldots \ldots \ldots \ldots \ldots \ldots \ldots \ldots \ldots$

13. Subject B: Pain Scores and Activities $\ldots \ldots \ldots \ldots \ldots \ldots \ldots \ldots$

14. Subject B: Grip / Pinch Scores $\ldots \ldots \ldots \ldots \ldots \ldots \ldots \ldots \ldots \ldots$

15. Subject C: Pain Scores and Activities $\ldots \ldots \ldots \ldots \ldots \ldots \ldots \ldots \ldots$

16. Subject C: Grip / Pinch Scores $\ldots \ldots \ldots \ldots \ldots \ldots \ldots \ldots \ldots \ldots$

17. Subject D: Pain Scores and Acitivities $\ldots \ldots \ldots \ldots \ldots \ldots \ldots \ldots$

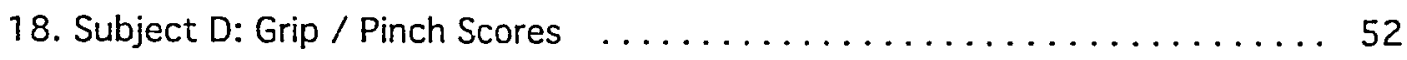

19. Subject E: Pain Scores and Activities . . . . . . . . . . . . . 54

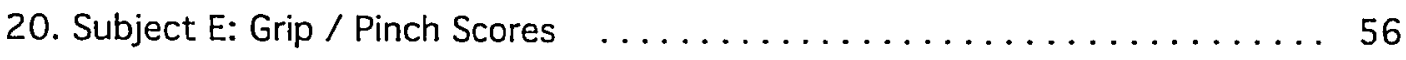

21. Subject A. Pain and Function Scores $\ldots \ldots \ldots \ldots \ldots \ldots \ldots \ldots$

22. Subject B: Pain and Function Scores $\ldots \ldots \ldots \ldots \ldots \ldots \ldots \ldots \ldots \ldots \ldots \ldots$ 
23. Subject $C$ Pain and Function Scores $\ldots \ldots \ldots \ldots \ldots \ldots \ldots \ldots \ldots \ldots \ldots$

24. Subject D: Pain and Function Scores $\ldots \ldots \ldots \ldots \ldots \ldots \ldots \ldots \ldots \ldots \ldots \ldots \ldots \ldots$

25. Subject E: Pain and Function Scores $\ldots \ldots \ldots \ldots \ldots \ldots \ldots \ldots \ldots$ 


\section{CHAPTER 1}

\section{INTRODUCTION}

\section{Purpose}

The purpose of the study was to determine the effectiveness of two types of splints, the short hand-based thumb splint and the long wrist thumb splint, which are commonly prescribed for the conservative medical management of thumb carpometacarpal (CMC) joint arthritis, and to determine the effectiveness of the splinting on pain and hand function as compared with no splinting.

\section{Statement of the Problem}

The CMC joint of the thumb is the most important joint in the hand for normal hand function (Burton, 1986). "The critical angle and range of the thumb projection from the fixed unit of the hand is dependent on the basal joint integrity" (Burton, 1986, $p$. 493). Since the CMC joint is the most proximal joint of three thumb joints, laxness caused by ligament destruction or joint collapse, and altered mechanical advantage of the extrinsic and intrinsic muscles promotes zig-zag deformities in the distal joints of the thumb (Flatt, 1983). Deficits in the area of hand function affect human performance in daily living skills and affect behavior and the person's roles.

It is assumed by therapists that the goals of splinting in cases of CMC arthritis are to increase hand function and decrease pain (Melvin, 1982). CMC joint arthritis is a common disorder presented to hand surgeons and hand rehabilitation therapists. Splinting is a practical, useful, conservative treatment used by hand rehabilitation therapists for CMC joint pain and dysfunction; however, it has not been studied to identify the type of splint that would be most effective in achieving the goals of decreased pain and increased hand function. The short hand-based splint is used to position the thumb in a neutral, resting position, while the long CMC thumb splint is used to position the thumb and immobilize the wrist. A controversy between splinting for stability and 
position of the CMC joint with a short hand-based splint and splinting to incorporate the wrist in thumb opposition exists. This research addresses this controversy.

\section{Research Questions}

The research questions were "What is the effect of the long wrist thumb splint and the short hand-based thumb splint on hand function and pain in patients with thumb CMC joint arthritis? What is the perceived pain relief during functional activity using the two types of splint during the activities as compared to the unsplinted thumb and hand during the activities?

\section{Operational Definitions}

Definition of the terms used in this study were:

Carpometacarpal (CMC): The trapeziometacarpal joint at the base of the thumb. The CMC joint may be referred to as the basal joint (see Figure 1).

CMC Hand Function Test: A series of non-standardized hand function tasks used in the study. Opening jar, opening a bottle, turning a key, turning a door knob, and using scissors are activities which required high use of the CMC joint of the thumb.

Dynamometer: A Jaymar model dynamometer, calibrated in pounds and kilograms used to measure hand grip strength or force.

Functional activity: The performance of tasks such as writing, turning cards, picking up small and large items, turning a key, was tested in this research. All the activities were evaluated as to level of pain.

Hand based thumb splint: A short opponens splint, volar and dorsal which immobilizes the CMC and metacarpal phalangeal (MP) joint in a resting position while allowing motion at the thumb interphalangeal (IP) joint (see Figure 2).

Jebsen Hand Function Test: A timed standardized test which consists of 7 subtests which were used to assess hand function (Jebsen, 1969). 


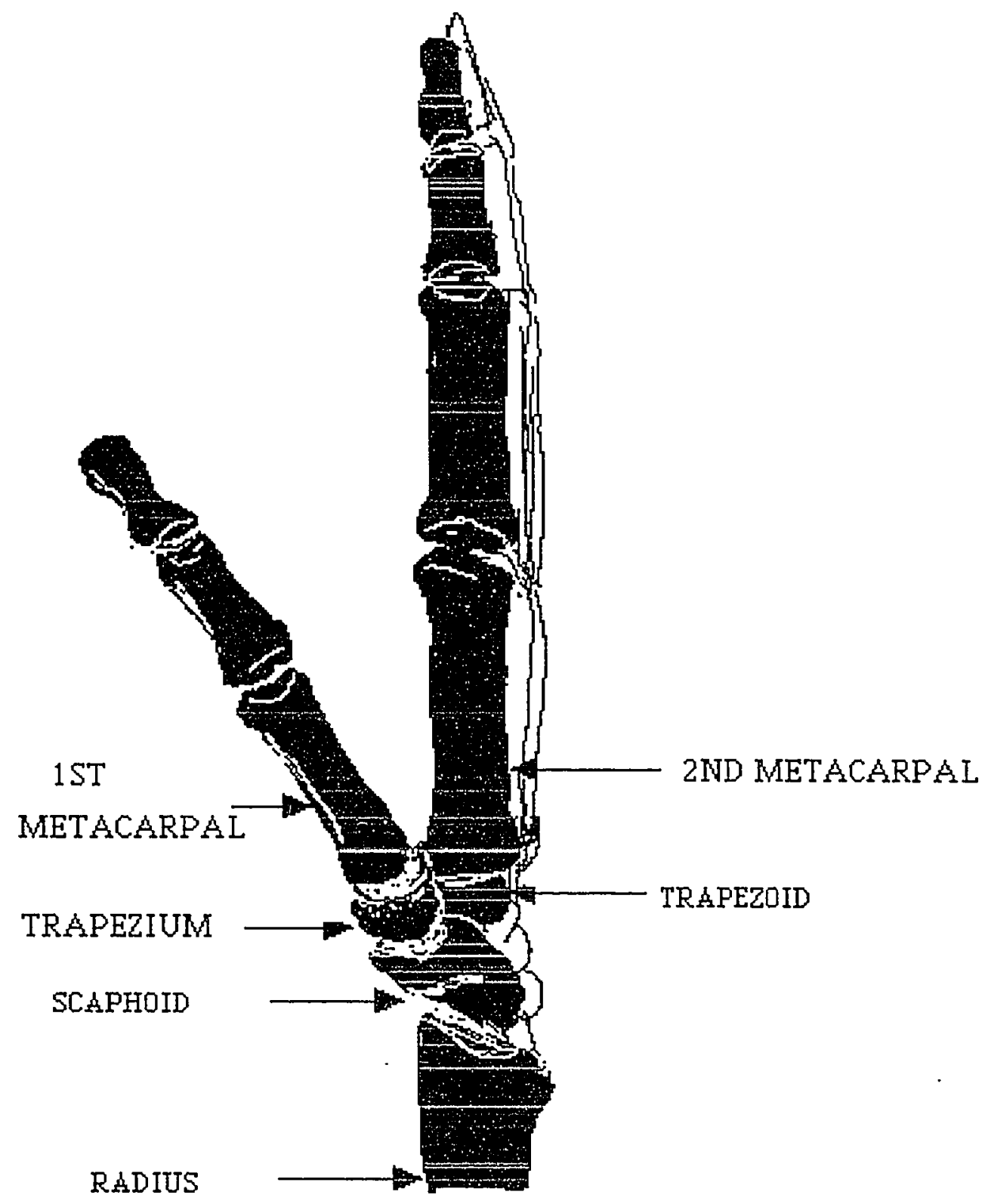

Radial View

Figure 1. Carpometacarpal joint at the 1st metacarpal and trapezium. Adapted from Agur, A. M., Grant's Atlas of Anatomy. 
Lateral pinch: It is also called a key pinch. The position measured when the pad of the thumb presses against the radial side of the index finger near the proximal interphalangeal joint (Smith \& Benge, 1985).

Long wrist thumb CMC splint: The combination of 2 splints, the short hand-based splint and a prefabricated wrist splint to immobilize the wrist, the CMC, and MP joints in the resting position of the wrist and hand (see Figure 3).

Neutral or resting position of the wrist and hand: The forearm position of midposition, half way between supination and pronation, wrist in 10 degrees of extension with the third metacarpal aligned with the radius, all digits flexed 45 degrees at all the joints. The thumb pulp is positioned beside the middle segment of the index finger and thumb nail at right angles to the plane of the palm (Brand, 1985).

Osteoarthritis: For this study osteoarthritis, or conditions that produce inflammation of the CMC was studied. Arthritis is inflammation of bone and the surrounding tissue.

Palmar pinch or three jaw chuck: The type of movement created by the opposition of the thumb and the index and middle fingers and measured by the pinch gauge (Smith \& Benge, 1985).

Perceived Pain relief: Level of pain measured by a visual analog scale.

Pinch gauge: A tool calibrated in pounds or kilograms that measures lateral or palmar pinch strength.

Position of function for the CMC joint: Position created when the CMC joint surfaces are congruent, the position of the thumb in full abduction or adduction and the joint is held by tense capsular and ligamentous structures (Flatt, 1979).

Position of rest for the CMC joint: Position used to splint the thumb CMC joint. The CMC joint was in midposition, (the position between abduction, adduction and between flexion and extension). 


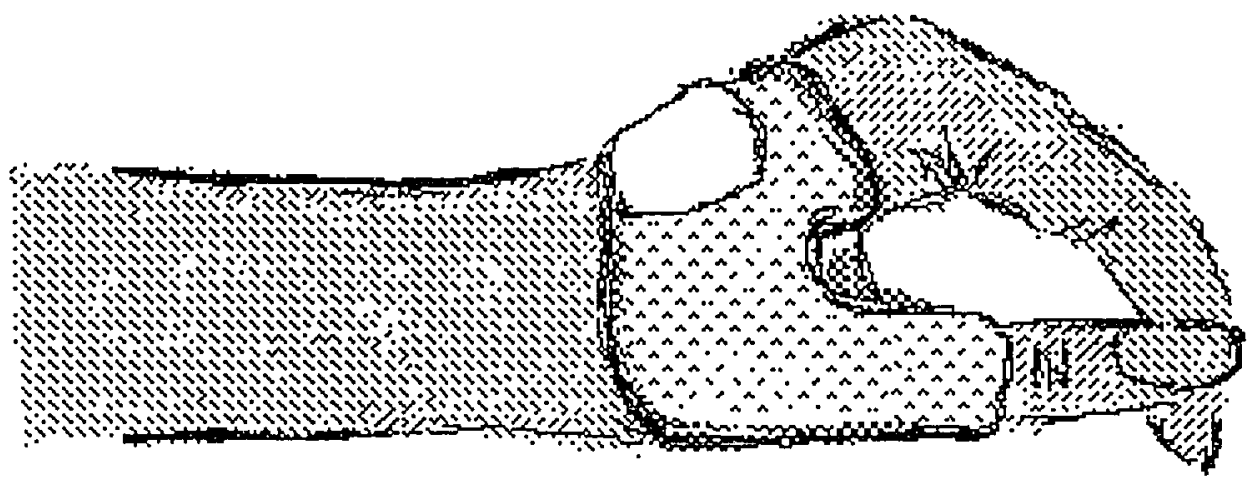

Figure 2. Short Hand-Based Thumb Carpometacarpal Splint. The splint is custom made, of a lightweight, perforated thermoplastic material which is molded to the person's hand. 


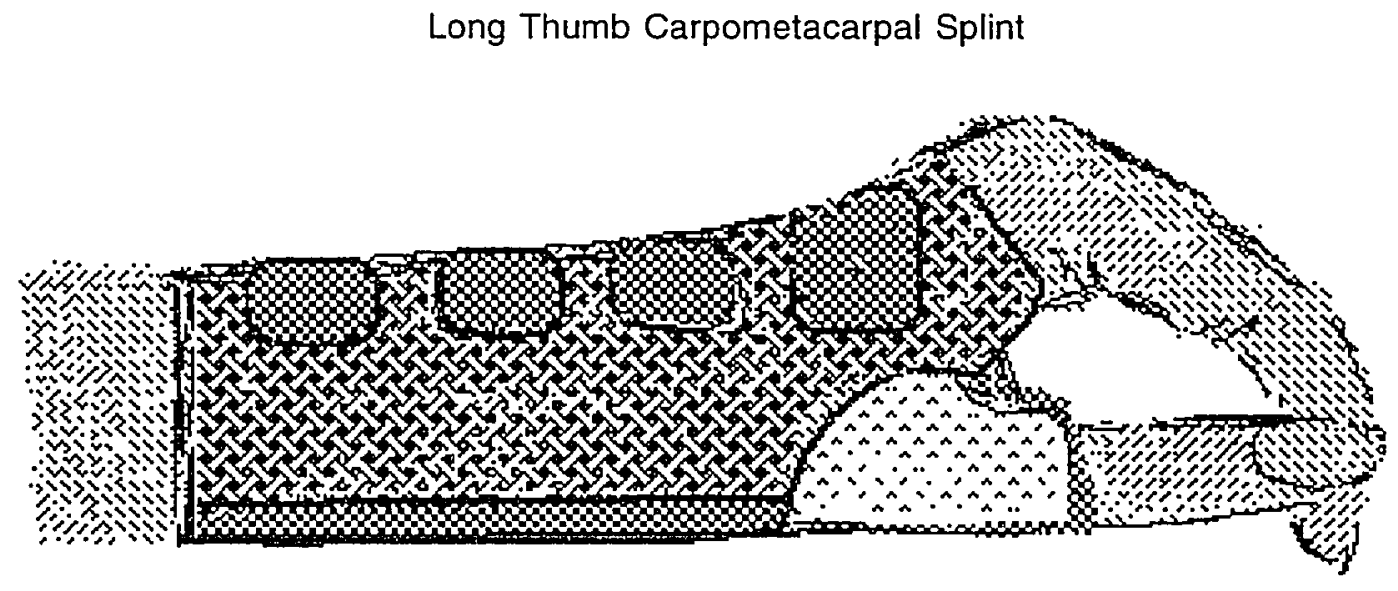

Figure 3. The long carpometacarpal splint consists of a commercial wrist splint over the short CMC splint. 
Thumb carpometacarpal (CMC) joint arthritis: Inflammation and degeneration of the trapezium and first metacarpal and may include the inflammation and bone degeneration of other carpal bones.

Visual analog pain scale: A measure of pain on a $10 \mathrm{~cm}$. line which was measured from 0 (no pain) to 10 (severe pain).

\section{Assumptions}

The assumptions held by the researcher for this study were:

1. Patients had been correctly diagnosed with thumb CMC arthritis by the physicians.

2. Splinting is an appropriate treatment intervention for thumb CMC arthritis for the purpose of decreasing pain and increasing function.

3. The technique used to position the patient in the splint and the position of the thumb was correct, and the materials used were adequate.

4. The position of rest for the wrist and thumb was assumed to be the most therapeutic position to stabilize the CMC joint and balance the mechanical forces acting on the injured thumb. Since the injured hand is not normal it should not be placed in a functional position (Flatt, 1979). Brand's (1989) definition of the neutral or resting position was used in splinting the wrist and thumb.

5. The technique used in splinting achieves the resting position described by Brand without assistance in positioning by the patient.

\section{Limitations}

The limitations of the study are:

1. The five subjects used in the study were a sample of convenience and representative of a small population and one can not infer that the results of the study are reflective of all patients with thumb carpometacarpal arthritis.

2. The administration of the Jebsen Hand Function test was altered from: 
a) recommended order of non-dominant, dominant hand.

b) 1 1/4 inch paper clips were used instead of 1 inch paper clips.

c) the table top was used instead of a bookstand.

d) after the first administration the test was not administered verbatim each successive time.

These conditions are acknowledged as variances from the standardization of the test and may alter hand function time and results.

3. The CMC hand function test is a non-standardized test used as a quick test to assess thumb carpometacarpal pain which was developed by the researcher for this study. The data from these tests are descriptive. The results of these data were for inference and possible future studies.

4. Certain conditions such as choice of splints, thumb position, splint material and method of splint constructions are variables that could affect the results of another study conducted by another therapist.

Significance of the Study

The thumb is one of 5 digits of the hand; however, its loss or amputation constitutes $40 \%$ of the impairment of the hand (American Medical Association, 1958). The carpometacarpal joint is a universal joint and biomechanically very complex in form and function. It is important for most of the prehension patterns and fine motor skills used in daily activities. Thumb CMC arthritis is a condition which can occur because of instability of the joint and can lead to premature degenerative changes (Eaton, Lane, Littler \& Keyser, 1984). This is also a diagnosis which occurs frequently in post menopausal women (Aulicino \& DuPuy, 1984; Flatt, 1983). It occurs as a result of occupational and recreational activities where the thumb in hand function is in high demand, such as on an assembly line or in sports such as tennis and golf (Burton, 1986). This study is significant for determining whether splinting is a practical, 
useful, conservative treatment modality used by hand therapists for $\mathrm{CMC}$ joint pain and dysfunction. The type of splint generally requested by physicians will vary from the short hand-based splint to the long, wrist-thumb splint for full wrist immobilization. Splinting the wrist should prevent the kinematic chain of movement of the first metacarpal and trapezium, and other carpal, radial and ulnar joint articulations and also eliminate tenodesis movements. This study provides information and insight into splinting and treatment of the CMC joint of the thumb and should generate further study. 


\section{CHAPTER 2}

\section{LITERATURE REVIEW}

Introduction

Literature in several related areas was reviewed. The anatomical and biomechanical literature on the thumb CMC joint, osteoarthritis, occupational therapy theory and frames of reference and intervention of splinting, the assessment of upper extremity functional activities as it applies to daily living, and an assessment of pain as it relates to upper extremity function was reviewed. The literature on CMC splinting was scarce and no studies were found on splinting of the thumb CMC joint.

Anatomy and Biomechanics

"The carpometacarpal is the key joint of the thumb." (Flatt, 1983, p. 226). A stable and pain free CMC or basal joint, is important because it is the only joint of the thumb which is normally capable of lateral and rotary motion (Eaton et al., 1984). The joint is a biconcave joint with strong ligament support that allows for stability during pinch and grasp (Imaeda, An \& Cooney, 1992). This joint is composed of two articulating surfaces which are concave (trapezium) and convex (metacarpal) and unlike other saddle joints is not congruent (Napier,1955). When the thumb is in a resting position or mid position the articular surfaces are incongruent and the ligaments are relaxed. In the incongruent position of the trapeziometacarpal, the joint rests on a point contact and converts to a state of congruency or greater trapezial metacarpal joint contact in abduction, adduction and circumduction (Napier 1955). The trapezium is uniquely configured to permit 2 planes of motion, plus rotation which is the mechanical equivalent of a universal joint (Cooney, Lucca, Chao \& Linscheid, 1981; Imaeda, et al., 1992). Napier (1955) describes opposition in a functional sense. It is the movement which results in the pulp surface of the thumb becoming diametrically opposed to the pulp surface of one of the other remaining digits for the purpose of prehension. In hand 
function, thumb abduction allows precision and power is secondary. During precision movement the thumb provides the stability to the grip by opposing one or the other of the digits. If the need for strength and power is required, the thumb is adducted as in a lateral pinch by the function of the strong adductor pollicis (AP) (Brand, 1985). There are two pathways for precision pinch, the direct pathway and the indirect pathway. The direct pathway is achieved by moving the first metacarpal and is used for small objects stabilized between the thumb and fingers. The indirect pathway is used for large objects when the thumb is first abducted at the CMC joint and circumducted in an ulnar direction (Napier, 1955).

In pinch, when the force is at the end of the digits the stabilization of the joint at the CMC by the adductor pollicis is important (Brand, 1985). The muscles also help to stabilize but also create a force on the thumb that can cause deformities if ligamentous stability is lacking. A deformity that often occurs is the dislocation of the first metacarpal at the trapezium. The two main forces acting on the first metacarpal are the adductor pollicis (AP) and the abductor pollicis longus (APL). When an object is held by the adductor pollicis (AP) as in a strong lateral pinch, the APL by its insertion at the base of the first metacarpal exerts a dislocating force on the first metacarpal (Brunelli, 1989).

In a biomechanical analysis of the static forces in the thumb during hand function, Cooney and Chao (1977) conducted a 3 dimensional analysis of the internal forces in the joints and soft tissue of the thumb during pinch and grasp and found that there is approximately 12 times the force at the CMC for each kilogram of force applied to the tip of the thumb. In a study using normal cadaver specimen, the authors ascribed mechanical equivalents to the anatomical systems, joint orientation and tendon locations from biplanar roentgenograms. They calculated the magnitude of forces in tendons, intrinsic muscles, joint contact surfaces and constraining ligaments on assumed loads 
applied to the tip of the thumb in tip pinch, lateral pinch, palmar pinch and grasp. The joint compression forces averaged 3 kilograms at the interphalangeal (IP), 5.4 kilograms at the metacarpal phalangeal (MP) and 12 kilograms at the CMC joint for 1 kilogram of applied force. Compression forces at the CMC can be as much as 120 kilograms in a strong grasp (Cooney \& Chao, 1977).

Although this study was conducted on a cadaver, the implication for understanding the CMC joint in hand function and on activities of daily living are significant. Joint compression forces of 1 kilogram which seem benign are actually 12 kilograms at the CMC joint and compression forces over time with work, recreational, and daily activities can lead to $\mathrm{CMC}$ joint dysfunction and dislocation.

\section{Splinting}

Splinting is a treatment modality used by the occupational therapist or hand therapist and is a complex field of applied biomechanics. "Splinting requires the application of external forces to the extremity" (Fess, 1987, p. 125). There are individual considerations in all cases and each situation may have different secondary complications and disease process. In splinting, the mechanical principles, design principles and application are often dependent on the individual and the goals of splinting. In general the mechanical principles which were identified by Fess (1987) are:

1. Reduce pressure by increasing the area of force application.

2. Control parallel force systems by increasing mechanical advantage.

3. Use optimum rotational force when mobilizing a joint by dynamic traction.

4. Consider the torque effect on a joint.

5. Consider the relative degree of passive mobility of successive joints within the longitudinal segmental kinematic chain.

6. Consider the effects of reciprocal parallel forces when designing splints and 
placing straps.

7. Increase material strength by providing contour.

8. Eliminate friction.

9. Avoid high stress (p.125).

In the selection of the appropriate splint for thumb carpometacarpal disorders, the following information is important regarding specific principles of design (Fess, 1987, p. 187).

1. Identify the key joint.

2. Review the purpose: to immobilize, increase passive motion; or substitute for active motion.

3. Determine if the wrist should be incorporated.

4. Consider kinetic effects.

5. Identify areas of diminished sensibility.

6. Decide whether to employ static or dynamic forces.

7. Determine the surface for splint application.

8. Use mechanical principles advantageously.

9. Adapt for anatomic variables.

10. Choose the most appropriate materials.

11. Adapt to the general properties of the selected splint materials.

\section{Arthritis}

According to Fries (1988) there are several categories of arthritis. One of these categories, cartilage degeneration, is also known as osteoarthritis, degenerative joint disease, and osteoarthrosis. This joint change is a condition that usually occurs with age in both men and women. In many cases the pain of thumb carpometacarpal joint is associated with hypermobility of the joint. Persistent hypermobility predisposes the joint to trauma and damage to the articular surface. 
The CMC joint degeneration classification system described by Eaton, et al., 1984, was academically useful in understanding the degeneration of the trapeziometacarpal joint. The classification is made through radiographic analysis. The trapezium and the scaphotrapezium joints are reviewed on a lateral radiograph. (Eaton, et al., 1984). The stages are:

Stage I - Articular contours are normal and joint space may be widened.

Stage II - Slight narrowing of the trapeziometacarpal joint of the thumb, but articular surfaces are maintained. Joint debris is less than $2 \mathrm{~mm}$. in size. Stage III - Sclerotic and cystic degenerative changes are often seen in the subcondral bone; osteophystes are greater than $2 \mathrm{~mm}$. in size, scaphotrapezial joint surfaces appear normal.

Stage IV - The scaphotrapezial joint also exhibits degenerative changes in addition to the trapeziometacarpal joint of the thumb. There may be multiple diseased articular surfaces.

\section{Assessment of Pain}

The perception of pain and its measurement is difficult and many studies have been done to test the reliability and the validity of identifying pain perception. There are several detailed pain assessments that rely on subjective judgments, i.e., the verbal category, visual analog scales, and the ratio scales developed with scaling techniques (Bradley, Anderson, Young \& Williams, 1989). The most commonly used method is the category scales. This method requires patients to rate the intensity of their pain along a numerical $(1-10)$ or verbal scale (mild, moderate, severe). The visual analog scale method requires the patient to indicate pain perception by placing a perpendicular mark along a $10 \mathrm{~cm}$. line marked no pain at one end and unbearable pain at the other.

The McGill Pain Questionnaire (MPQ) is an assessment device that measures pain perception of the sensory, affective and intensity dimensions of pain. The MPQ consists 
of a 20 category scale of verbal descriptors, and the descriptors are ranked in order of pain intensity. The patient selects from each scale of descriptors which best describes his or her pain experience. Although widely used by health professionals, the draw back is the understanding of the English language by non English speaking subjects, and difficulty scoring (Bradley et al., 1989).

Swanson (1964) describes an impairment classification for pain which describes subjective pain from peripheral spinal nerve disorders symptoms as it interferes with the patient's activities. He rates pain in four categories: Minimal: 0-25\% (annoying), Slight: $26 \%-50 \%$, does it interfere with activity? Moderate: $51-75 \%$, does it prevent activity? Severe: $76 \%-100 \%$, does it prevent activity and also cause distress (Swanson, 1964)?

\section{Frames of Reference}

The occupational therapy conceptual frames of reference for this study are biomechanical (Reed, 1984, 1991), occupational performance (Pedretti \& Pasquinelli, 1990) and adaptive response. Reed $(1984,1991)$ and Hopkins (1988) described the biomechanical frame of reference which has a theoretical base in the physical sciences: of kinesis, kinematics, and medicine. Pedretti and Pasquinelli (1990) described the occupational performance frame of reference.

The adaptive response frame of reference is based on theory described by Maslow and King. It was developed as a frame of reference for occupational therapy theory by King (Reed, 1984, 1991). According to King, the client is in an internal or external stimulus response situation in which he or she performs an activity which if positive is a self-reinforcing feedback that will create his or her adaptive response. This frame of reference is important because freedom from pain is a basic need that motivates individuals to seek medical assistance and eventually surgery. The interest in this study is the physical, observable, functional behavior adjusted or adapted because of pain. 
The biomechanical approach was integrated into the systems theory of occupational performance through the motor functioning component which is a substructure of occupational performance. The substructures are: sensory integrative, motor functioning, social functioning, psychological functioning, and cognitive functioning (Pedretti \& Pasquinelli, 1990). Occupational performance is a conceptual frame of reference that addresses the individual's ability to accomplish the tasks related to roles of his or her developmental stage (Pedretti \& Pasquinelli, 1990). The deficits in occupational performance will cause dysfunction in functional performance of his or her daily activities, such as self-care, work, education and play and leisure (Pedretti \& Pasquinelli, 1990). Assessment is accomplished through interview, history, and performance testing. Treatment is through developmental understanding, competency, education and problem-solving (Reed, 1984, 1991).

The four stage treatment continuum described by Pedretti \& Pasquinelli, 1990 is as follows:

Stage One: Adjunctive Methods. These are procedures that prepare the patient for purposeful activities and are preliminary to the use of performance skills. Some of the procedures are exercise, facilitation, positioning, splinting, and physical modalities. Stage Two: Enabling Activities. These are activities that require the active participation of the individual; however, there is no inherent goal beyond the motor function that is required. Simulated activities, such as pegboards, and practice boards for clothing fasteners, and the Jebsen Hand Function Test (Jebsen, 1969) are examples of the enabling stage activities.

Stage Three: Purposeful Activities. These are activities that have an inherent goal and have meaning to the individual. Activities of daily living, work activities, communication and sports are examples of this stage. 
Stage Four: Occupational Performance, and Community Reintegration. In this stage the individual begins to resurne or assumes a role in his or her own environment and community. Higher level skills and tasks include self-care, work, education, play and leisure are resumed.

The occupational performance frame of reference incorporates the biomechanical and the adaptive response theories through the sensory integrative and motor functioning substructure of the paradigms. Biomechanical understanding of the wrist, hand, thumb anatomy, kinetics and kinematics, medicine and the arthritis disease process is necessary for the purposes of goal setting and treatment planning for use of therapeutic splinting. Although the dysfunction of the sensory and motor substructures is at a basic biomechanical and biochemical level, the principle of resonation in a hierarchical and interdependent systems theory, reflects how one substructure affects other substructures which eventually affects roles and social structures (Christiansen \& Baum, 1991).

Splinting and functional activities used in this study are Stage One (adjunctive methods) and Stage Two (enabling activities), respectively, in the occupational performance treatment continuum. Splinting is an activity that prepares and enables the individual to participate in purposeful activity. The Jebsen Hand Function Test (Jebsen, 1969) and grip and pinch tests are standardized activities that involve active participation and simulate everyday activities.

\section{Summary}

Splinting of the thumb and hand is an occupational therapy intervention commonly practiced; however, very little research has been reported. The CMC joint of the thumb is complex and very important to hand function. Arthritis and inflammation creates pain which affects hand function. At this time, there is no research by therapists on the 
specific topic of assessment of adjunctive splinting techniques for disorders of the thumb in occupational therapy as it relates to outcome of treatment for functional hand activities and pain.

This is a topic relevant to occupational therapists practically and theoretically because the understanding of the substructures in the occupational performance are important in the overall functional performance of the person within his or her environment. 


\section{CHAPTER 3}

\section{DESIGN ANDMETHODOLOGY}

\section{Research Questions}

The research questions were "What is the effect of the long thumb splint and the short hand based splint on hand function and pain in patients with thumb CMC joint arthritis? What is the perceived pain relief during functional activity using the two types of splints during the activities as compared to the unsplinted thumb and hand during the activities?"

\section{Research Design}

The research design used case study methodology to determine the status of the hand in the performance of functional activities and perception of pain with and without splints. The subjects were used as their own controls. (Oyster, Hanten \& Llorens, 1987). In the study, 5 patients constituted a sample of convenience. They were patients who were seen per physician referral from the Hand Clinic at Palo Alto Veterans Affairs Medical Center. The subjects were tested on functional performance without splints and then twice more, first with a short thumb splint and then with a long thumb splint. Splinting and testing were conducted by the same therapist. The subjects were tested while performing functional activities and rated their perceived pain on a visual analog scale. The functional activities used were the Jebsen Hand Function Test (Jebsen, 1969), grip and pinch test and a CMC hand function test. Time for each patient session was approximately 1 to 2 hours for 1 or 2 separate sessions.

\section{Procedure}

Patients were referred from the Hand Clinic at Palo Alto Veterans Affairs Medical Center to hand therapy for splinting of the CMC joint and hand evaluation. X-rays were interpreted by the referring physician to confirm the diagnosis of thumb carpometacarpal arthritis. Physicians relied on clinical judgment as well as evidence of 
arthritis in the X-rays. All subjects signed the San Jose Human Subjects consent form (Appendix B).

A short CMC splint was constructed for each subject. During the splinting process the subject was asked to relax his or her arm and allow the therapist to position the wrist, fingers and thumb. Splints were adjusted for comfort and fit before and during the evaluation period. Without constructing another splint, the long thumb splint was created by using a prefabricated wrist splint over the short hand-based splint. This was designed so that the position of the thumb would be the same in the comparison tests. Subjects were asked to describe location of pain other than CMC joint pain. Behavioral changes and functional adaptations were noted by the researcher.

Subjects were scheduled for appointments to assess hand function using the dynamometer, pinch gauge, CMC hand function test, Jebsen Hand Function Test (Jebsen 1969), and pain analog scale. The information from the tests was entered into a Thumb Carpometacarpal Data Sheet for each of the subjects. The sequence of testing no splint, short splint and long splint for all the subjects were the same.

The American Society of Hand Therapists' (ASHT) (1992) recommended method of grip measurement was used. in grip measurement, the upper arm was adducted next to the trunk and the elbow was flexed and the forearm was positioned in mid-position during the test using a dynamometer. Dynamometer position for grip was the secnnd grip position. In testing lateral pinch, the shoulder, elbow and forearm positions were the same. Palmar pinch was tested with the foreatim pronated instead of in mid-position. Lateral and palmar pinch weie tested using a commercial pinch gauge.

The CMC hand function test consisted of 5 activities: turning a key, opening a wide mouth jar, opening an aspirin bottle, turning a door knob, and using a pair of scissors. The tests were not timed but hand use was required of each subject. Subjects were rated as able to perform the task or not able to perform the task, i.e. pass / fail. Pain was 
rated on a visual analog scale. When subjects did not want to perform the task as pain avoidance, a 10 pain score was given.

In the Jebsen Hand Function Test (Jebsen, 1969), seven test items were designed to be representative of various hand activities. The subtests were designed to measure the left and right hands and each was to be administered in exactly the same manner with respect to positioning and instruction. All seven subtests were used and each test was timed with a stop watch.

A wooden board was necessary for subtests $4,5,6,7$. The Jebsen board dimensions of 41.5 inches long, 11 and $1 / 4$ inches wide and a $3 / 4$ inch thick was secured with nonskid material. The board was marked at 4 inch intervals for easy reference for placing objects. A center piece of the plywood, 20 inches long and 2 inches high and $1 / 2$ inch thick was glued to the board 4 and $5 / 8$ inches from the right end and 6 inches from the front of the board. The front of the center upright was marked at two inch intervals for convenience in placing objects. The table used for testing was marked and measured for the various subtests so that the placement of objects would be as consistent as possible. The test was modified for use in the study of the injured hand, but instruction in this thesis is given for the left hand. Each subtest was repeated for three trials on the hand referred for splinting.

Different sentences used for Subtest 1 were: 1) The old man seemed to be tired. 2) John saw the red truck coming. 3) Whales live in the blue ocean. 4) Fish take air out of water.

\section{Subtest 1: Writing}

Materials: Clipboard with four pieces of unruled paper

Black ball point pen

Two sheets of $5 \times 8^{\prime \prime}$ index card with third grade level sentences Procedure: The subject is given a black ball point pen and 4 sheets of paper 
fastened one on top of the other, to a clip board. The sentence to be copied has 24 letters and is of third grade difficulty. The sentence is typed in all capital letters and centered on a $5 \times 8$ inch card. The card is presented face down on a table. After the articles are arranged to the comfort of the subject, the card is turned over by the examiner with an immediate command to begin. The item is timed from the word 'Go' until the pen is lifted from the page at the end of the sentence. The item is repeated. A different sentence is used for each trial.

Instruction: "Do you require reading glasses for reading? If so, put them on. Take this pen in your left hand and arrange everything so that it is comfortable for you to write with your left hand. On the other side of this card (indicate) is a sentence. When I turn the card over and say 'GO', write the sentence as quickly and as clearly as you can using your left hand. Write, do not print, do you understand? Ready? GO" (Figure 4).

Subtest 2: Card turning (simulated page turning)

Materials: Five $3 \times 5$ cards

Procedure: Five $3 \times 5$ index cards ruled on one side only are place in a horizontal row two inches apart on the desk in front of the patient. Each card is oriented vertically, 5 inches from the front edge of the desk. This distance is indicated on the side edge of the desk with a line. Timing is from the word 'GO' until the last card is turned over, no accuracy of placement after turning is necessary.

Instruction: "Place your left hand on the table, please. When I say 'Go' use your left hand to turn these cards over one at a time as quickly as you can, beginning with this one (indicate the card to the extreme right). You may turn them over in any way you wish and they need not be in a neat pattern when you finish. Do you understand? Ready? Go" (see Figure 5). 

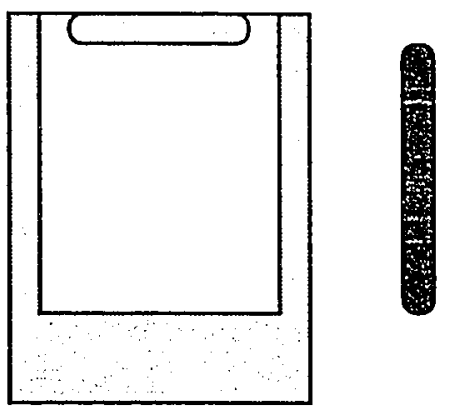

Figure 4. Jebsen Hand Function Test

Subtest 1: Writing 


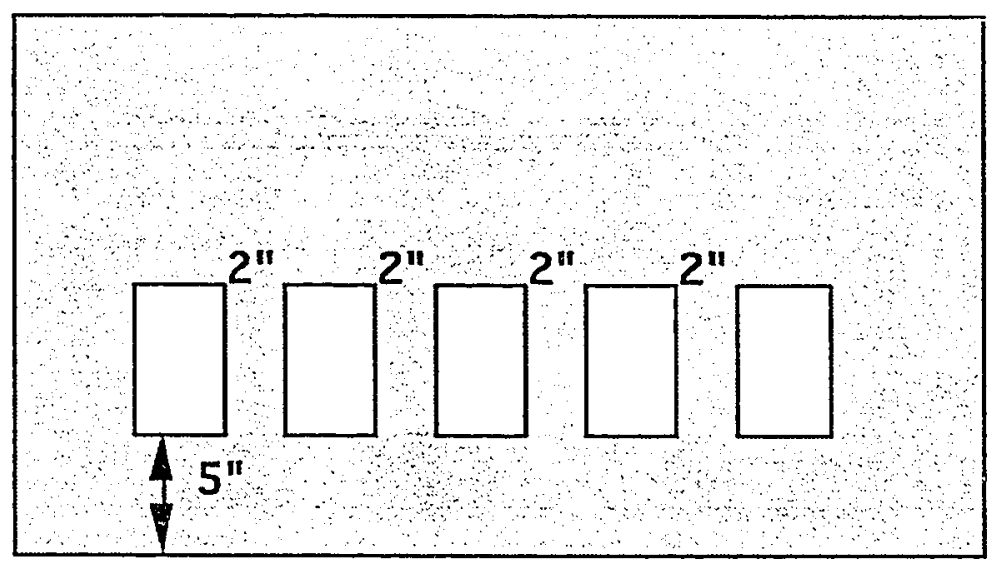

Figure 5. Jebsen Hand Function Test

Subtest 2: Card turning 
Subtest 3: Small common objects

Materials: 1 pound coffee can

Two 1 and $1 / 4$ inch paper clips

Two 1 inch bottle caps

Three pennies

Procedure: An empty 1 pound coffee can is place directly in front of the subject, 5 inches from the front edge of the desk. Two 1 and 1/4 inch paper clips (oriented vertically), two regular size bottle caps (each 1 inch in diameter and placed with the inside of the cap facing up) and two United States pennies are placed in a horizontal row to the left of the can. The paper clips are at the extreme left and the pennies, nearest the can. The objects are 2 inches apart. Timing is from the word 'Go' to the sound of the last object hitting the inside of the can. The item is repeated for the three trials. The layout is the mirror image of the one described with the objects to the right of the can.

Instruction: "Place your left hand on the table, please. When I say 'Go' use your left hand to pick up these objects, one at a time and place them in the can as fast as you can beginning with this one (indicate the paper clip on the extreme left). Ready? Go" (Figure 6).

Subtest 4: Simulated feeding

Materials: Jebsen board

Five kidney beans

One pound coffee can

One teaspoon

Procedure: Five kidney beans of approximately 5,8 inch in length are placed on a board in front of the subjects, 5 inches from the front edge of the desk. The beans are oriented to the left of center, parallel to and touching the upright of board and 


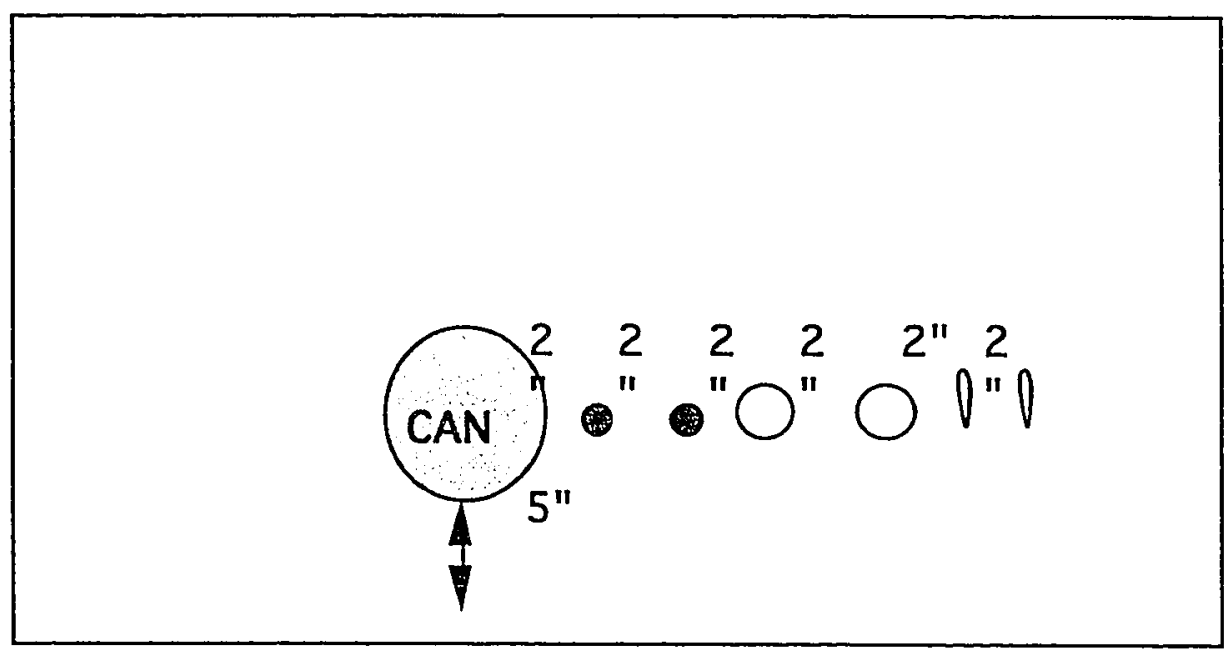

Figure 6. Jebsen Hand Function Test

Subtest 3: Small objects 
two inches apart. An empty one pound coffee can is placed centrally in front of the board. Timing is from the word 'Go' until the last bean is heard hitting the bottom of the can. The item is repeated with the three trials. The beans are placed to the right of center for the right hand.

Instruction: "Take the teaspoon in your left hand, please. When I say 'Go' use your left hand to pick up these beans, one at a time with the teaspoon and place them in the can as fast as you can beginning with this one. (indicate bean on the extreme right). Ready? Go" (Figure 7).

Subtest 5: Stacking checkers

Materials: Jebsen board

Four wooden checkers -1 and $1 / 4$ inches in diameter

Procedure: Four standard checkers are placed in front of and touching the board. The board is 5 inches from the edge of the desk. The checkers are oriented two on each side of the center in a OOOO configuration. Timing is from the word 'Go' to the time that the fourth checker makes contact with the third. The four checkers need not stay in place.

Instruction: "Place you left hand on the table, please. When I say 'Go' use your left hand to stack these checkers on the board in front of you as fast as you can like this, one on top of the other (demonstrate). You may begin with any checker. Do you understand? Ready? GO" (Figure 8).

Subtest 6: Large light objects

Subtest 7: Large heavy objects

(The set up and instructions for the large light and the large heavy objects are the same).

Materials: Jebsen board

Five empty (light) and five full (heavy) number 303 or 16 ounce cans. 


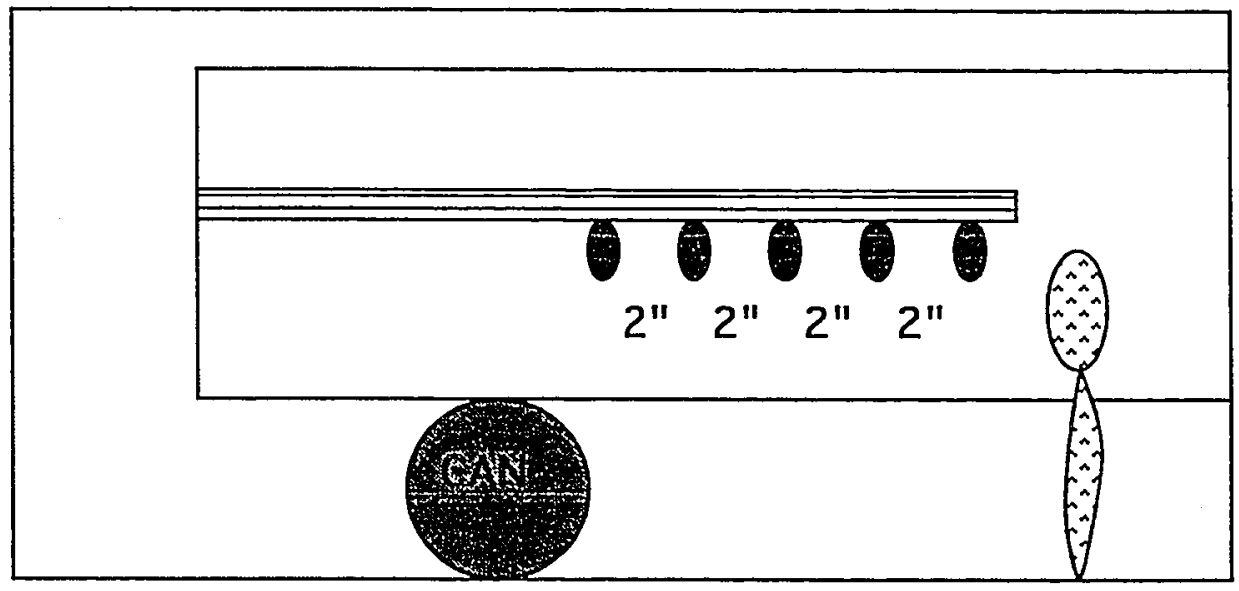

Figure 7. Jebsen Hand Function Test

Subtest 4: Simulated feeding 


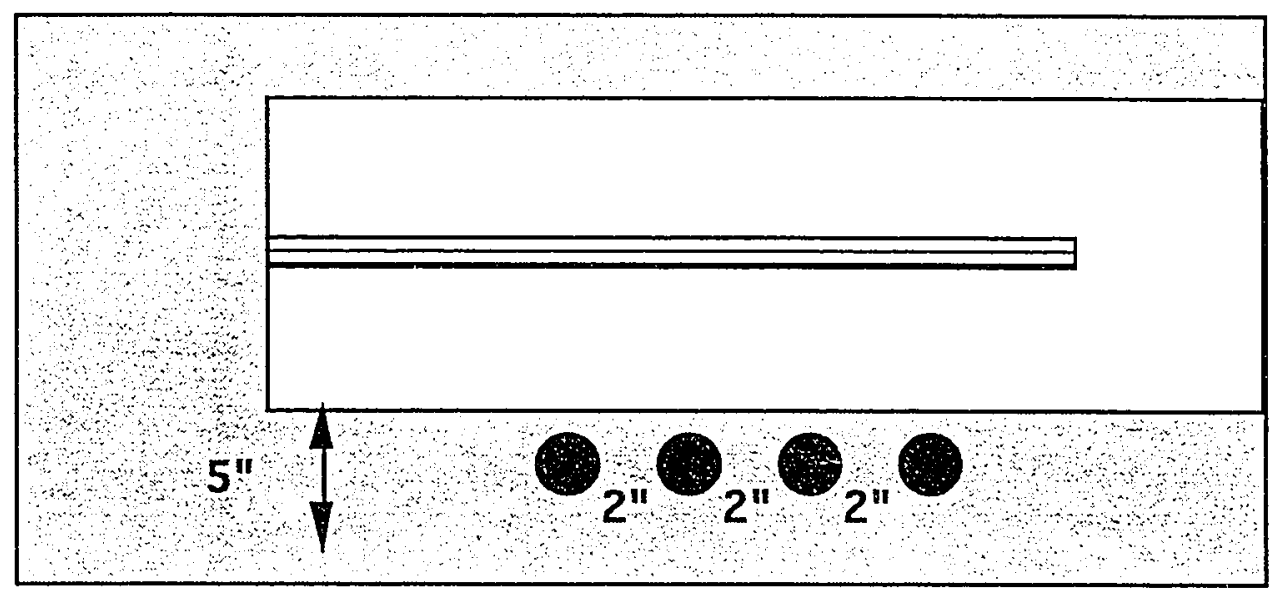

Figure 8. Jebsen Hand Function Test

Subtest 5: Stacking checkers 
Procedure: The five empty, number 303 (16 oz.) cans are place in front of the subject and in front of the board, which is five inches from the edge of the table. The cans are spaced 2 inches apart with the open end of the can facing down. Timing is from the word 'Go' until the last can is released. The item is repeated for each trial.

Instruction: "Place your left hand on the table, please. When I say ' Go', use your left hand to stand these cans on the board in front of you, like this (demonstrate). Begin with this one (indicate can on the extreme left). Do you understand? Ready? GO" (see Figure 9).

The pain scale form was explained to the patient before the evaluation. As each of the tests was given, a pain impairment classification was requested from the patient and responses were recorded. The patient was asked to verbally indicate the corresponding pain rating and to mark a $10 \mathrm{~cm}$. line where the perceived pain level was during the activity. Zero represented no pain and 10 severe pain. (Figure 10)

\section{Data Analysis}

Data were collected from February 25, 1993 to June 30, 1993 on 5 subjects. Subjects were referred from Hand Clinic at Palo Alto Veterans Affairs Medical Center. Data were entered on the Thumb Carpometacarpal Data Sheet as the subjects were tested. The room and the test set up were the same for each subject. The table was marked for consistent placement of the Jebsen subtests. Three subjects had their splints made and testing administered on the same day; two subjects had their splints made and tested in two days.

Information on the Thumb Carpometacarpal Data Sheet for each subject was analyzed (Appendices $B, D, E, F, G$ ). Pain was a continuous measure on the Visual Analog Scale. Data collected for motor function were continuous and discrete. The continous data were the Jebsen Hand Function (Jebsen 1969) subtest scores and grip and pinch 


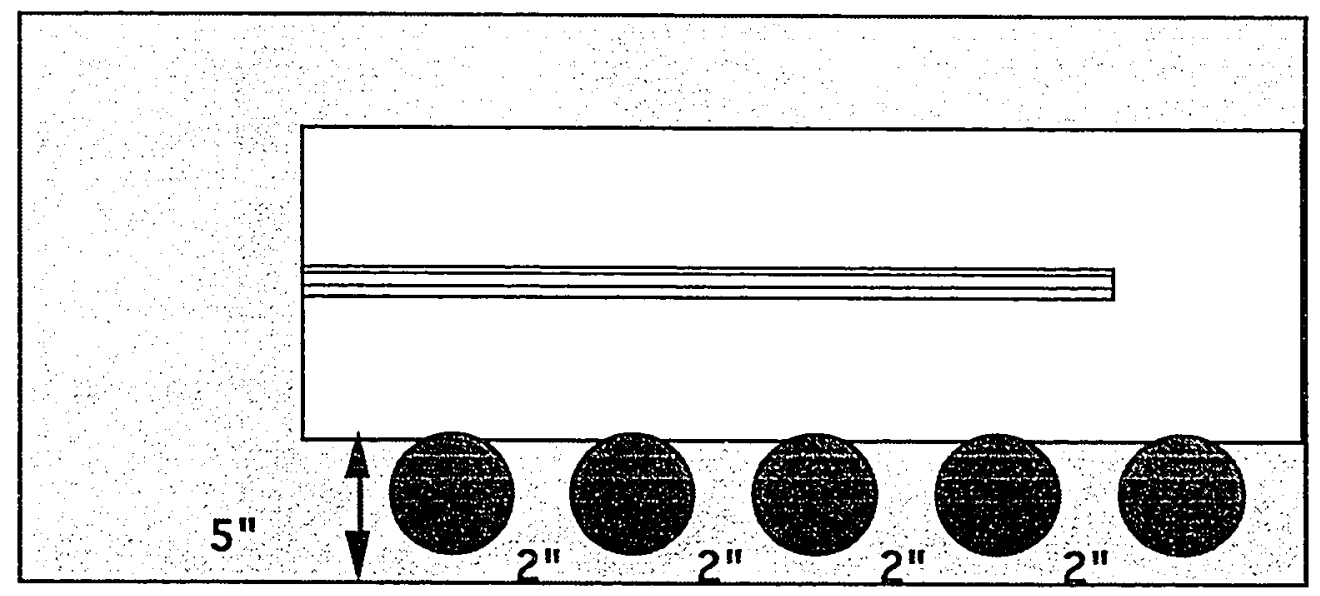

Figure 9. Jebsen Hand Function Test

Subtests 6 \& 7: Large light \& large heavy can set up is the same. 


\section{Pain Scale}

$$
\text { No Pain }
$$

Severe Pain

1. Grip

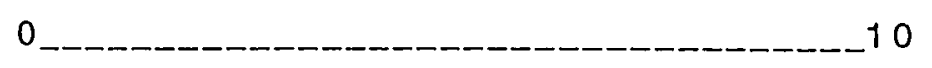

2. Lateral pinch

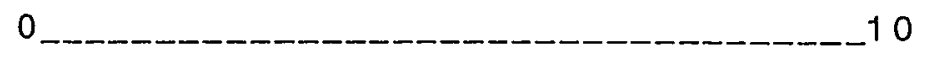

3. Palmar pinch

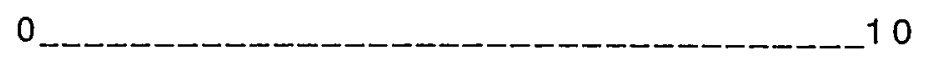

4. Writing

0

$-10$

5. Card turning

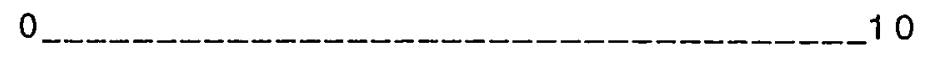

6. Small objects

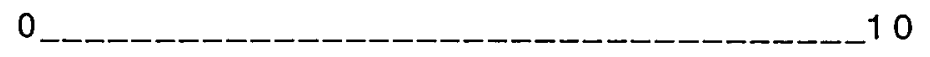

7. Sim. feeding

0

$-10$

8. Checkers

0 $-10$

9. Light objects

0 10

10. Heavy objects

0 $-10$

11. Turn key

0 $-10$

12. Open jar

0 $-10$

13. Aspirin bottle 0 10

14. Turn knob

$$
0
$$
$-10$

15. Use scissors

0

$-10$

Figure 10. Visual Analog Pain Scale (Graph is not drawn to scale of actual pain scale.) 
strength data. The CMC test activity data were discrete. Subjects were able to perform or not perform the activity. If subjects were able to perform the activity a score of ten (10) was given, if unable to perform or complete the task a zero (0) was given. 


\section{CHAPTER 4}

\section{DATA AND RESULTS}

\section{Presentation of Data}

Case data are reported to include demographics, such as age, hand dominance, injured hand, vocation, and severity of CMC arthritis. Results are presented per case data and results include information on pain, hand function, general observations and data analysis. The results are reported to answer the research questions posed in the study.

\section{Subjects}

Two women and 3 men participated in the study. All were very cooperative, physically active, ambulatory, independent in activities of daily living, and competent in their person to be able to sign a human subjects consent form. They were referred through the Hand Clinic at Palo Alto Veterans Affairs Medical Center with the diagnosis of thumb carpometacarpal arthritis. The age range was 36 to 75 . Some subjects had more medical problems due to age and disease process. In all cases the thumb had been painful for months before medical treatment was sought. In one case the pain was severe enough for immediate surgery. In 3 of the 5 cases there was bilateral pain in the CMC joint.

Case A

\section{Demographics}

Case $A$ is a right handed, 36 year old woman, who was clinically diagnosed with the beginnings of thumb CMC inflammation and referred for splinting and hand function evaluation for her right hand. Although $X$-rays were not conclusive, she was being treated for CMC arthritis. She is a therapist who was having pain in her thumb. She was splinted and tested in one session.

\section{Pain}

Her left, non-dominant hand was tested first; however, she also had pain in her left 
thumb CMC joint. With her right hand, she experienced pain with grip at $3.80 \mathrm{~cm}$., lateral pinch at $2.00 \mathrm{~cm}$., palmar pinch at $2.70 \mathrm{~cm}$., and the key turning activity at $3.10 \mathrm{~cm}$. with the no splint procedure. She had no pain with the short and the long splints (see Figure 11). She experienced discomfort with splints in other parts of her hand and arm during the tests but not in the area of the CMC joint. In the long splint test she experienced slight pain with picking up large light and large heavy objects in the forearm and the distal thumb joint (see CMC data sheet, Appendix B). Pain was greatest with the no splint condition with the activities of grip, lateral pinch and palmar pinch, and turning a key.

Function

In comparing Subject A's scores for the Jebsen Hand Function Test (Jebsen, 1969) in the three conditions of splinting, the finding was that the unsplinted hand performed in the fastest time; the short splint was second, and the long splint was the least efficient (see Table 1). She performed within the Jebsen Hand Function normative range (within 1 standard deviation) for the dominant hand, in the no splint and short splint condition (Appendix C). She was slightly under the normative range with the long splint in card turning and in picking up large light and large heavy objects.

Grip strength measurements were: no splint, 64.50 pounds; short splint, 71 pounds; and long splints, 50.50 pounds. Lateral pinch measurements were: no splint, 17 pounds; short splint, 16 pounds; and long splint, 15.50 pounds. Palmar pinch measurements were: no splint, 22.50 pounds; short splint, 16.50 pounds; and long splint, 17 pounds. In comparing grip and pinch with the three conditions, grip was increased with the short splint and decreased with the long splint. Lateral pinch function decreased 1 pound with short splint and 1.50 pounds with the long splint. Palmar pinch diminished 6 pounds with the short splint and 5 pounds with the long splint (see Figure 12). She was able to perform all of the CMC hand function tests. 
SUBJECT A: Relationship of Pain Scores and Activities for the Three Conditions of Splinting.

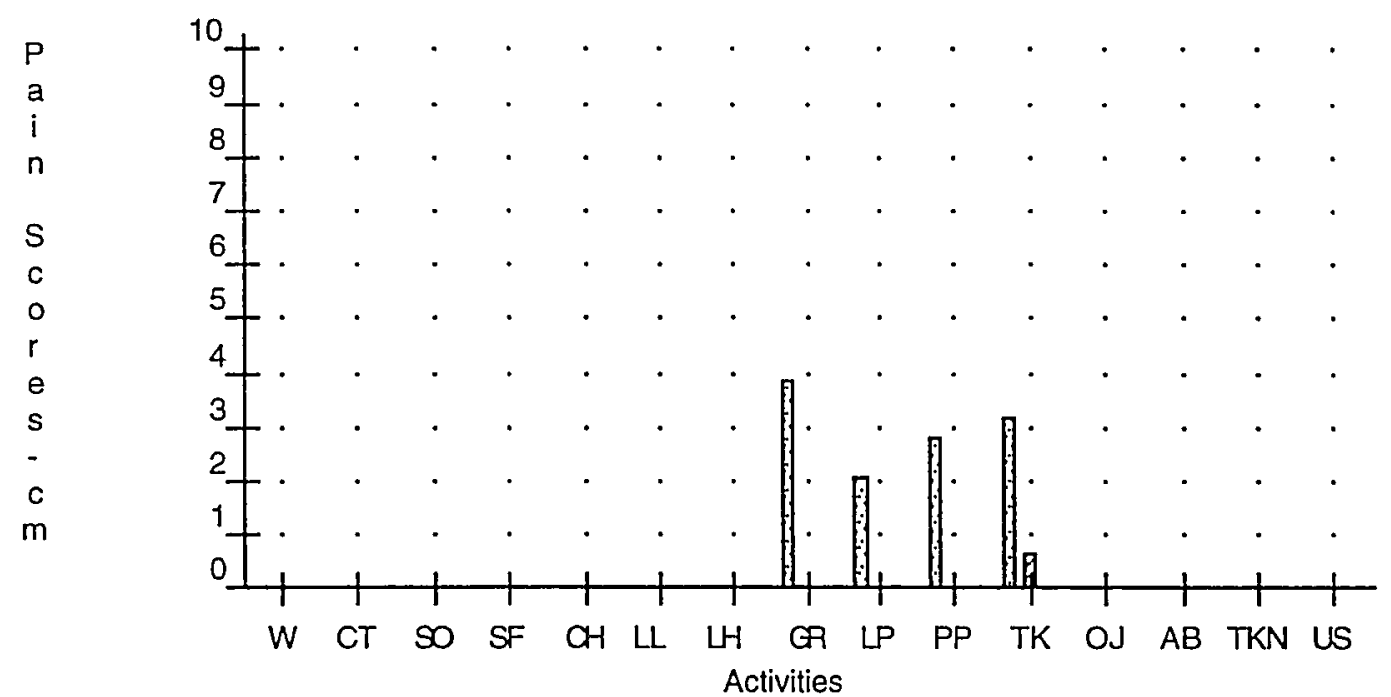

\section{NNO SPLINT 『SHORT SPLINT QLONG SPLINT}

Legend:

$\begin{array}{ll}\text { W - Writing } & \text { LP - Lateral pinch } \\ \text { CT - Card turning } & \text { PP - Palar pinch } \\ \text { SO - Small objects } & \text { TK - Turn key } \\ \text { SF - Simulated feeding } & \text { OJ - Open jar } \\ \text { CH - Checkers } & \text { AB - Asprin Bottle } \\ \text { LL - Large light objects } & \text { TKN - Turn knob } \\ \text { LH - Large heavy objects } & \text { US- Use scissors } \\ \text { GR - Grip } & \end{array}$

Figure 11. Subject A: Pain Scores for All Activities for the Right Hand. 
Table 1

Subject A: Jebsen Hand Function Scores in Seconds for the Three Conditions of Splinting

\begin{tabular}{llll}
\hline Jebsen Subtest & No Splint & Short Splint & Long Splint \\
\hline Writing & $6.25 \mathrm{sec}$. & $8.25 \mathrm{sec}$. & $11.50 \mathrm{sec}$. \\
Card Turning & $3.75 \mathrm{sec}$. & $4.00 \mathrm{sec}$. & $6.00 \mathrm{sec}$. \\
Small objects & $5.00 \mathrm{sec}$. & $5.00 \mathrm{sec}$. & $6.00 \mathrm{sec}$. \\
Feeding & $7.25 \mathrm{sec}$. & $6.50 \mathrm{sec}$. & $6.50 \mathrm{sec}$. \\
Checkers & $2.50 \mathrm{sec}$. & $3.25 \mathrm{sec}$. & $3.50 \mathrm{sec}$. \\
Large light objects & $3.00 \mathrm{sec}$. & $3.50 \mathrm{sec}$. & $5.75 \mathrm{sec}$. \\
Large heavy objects & $2.25 \mathrm{sec}$. & $3.50 \mathrm{sec}$. & $5.00 \mathrm{sec}$. \\
\hline
\end{tabular}


Subject A: Relationship of Grip and Pinch for the Three Conditions of Splinting as Measured by Pounds of Force

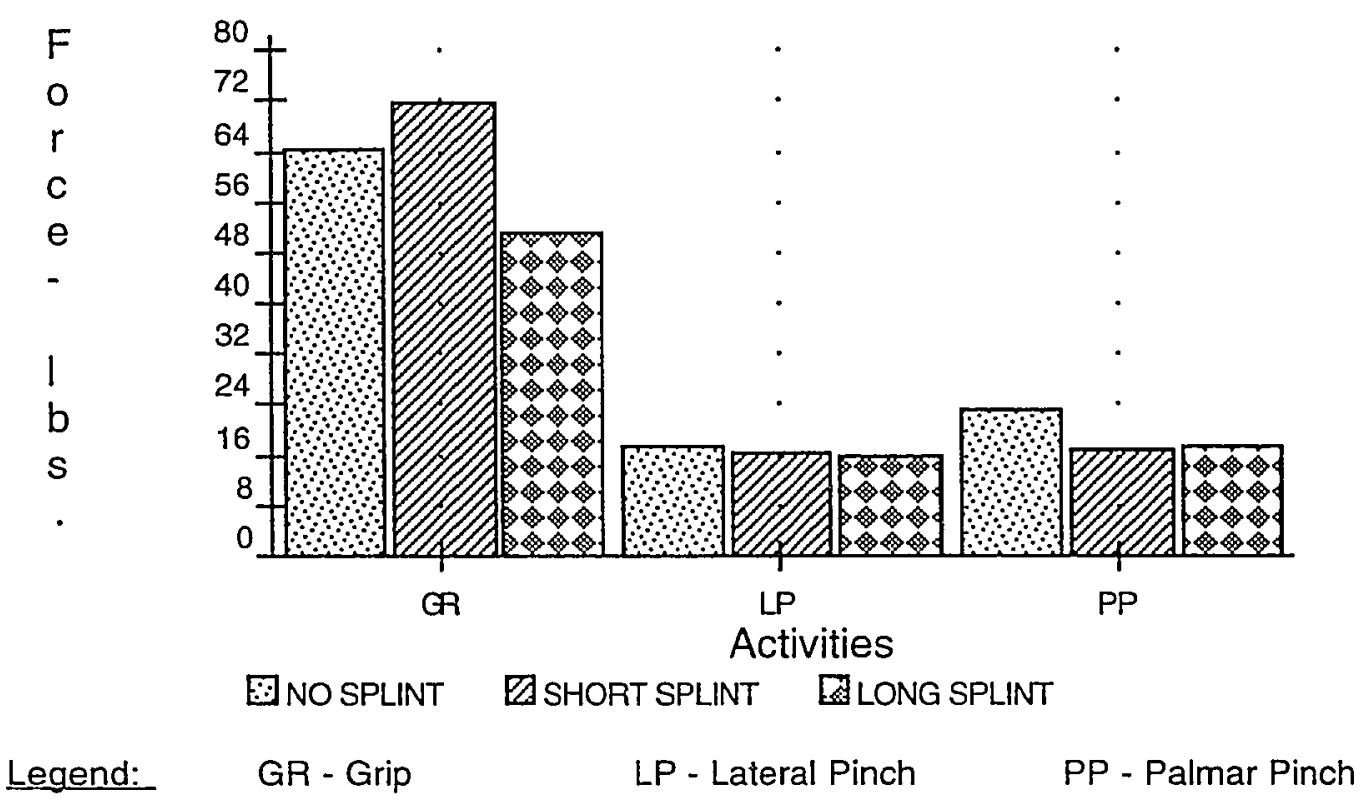

Figure 12. Subject A: Grip, Lateral Pinch and Palmar Pinch Scores for the Right Hand. 


\section{General Observation}

Case A was not taking any pain medication. In observing her movements during the splinted sessions, she increased shoulder and elbow movements to compensate for the lack of wrist movement with the long splint. This may also have accounted for her discomfort in the forearm and distal thumb joint during the test. She reported that her thumb is less painful with the short splint and she uses her splint during activities when she feels that she will be overusing her hand.

\section{Case B}

\section{Demographics}

Subject $B$ is a 64 year old, ambidextrous, retired man who was diagnosed with bilateral thumb CMC joint arthritis. At the time of the study, he was two weeks post surgery for a left thumb CMC arthroplasty and was still in a cast. His left hand was not tested. He was diagnosed and referred for splinting for his right hand. His diagnosis was confirmed by $X$-ray. He was tested in one day but in two separate sessions.

Pain

In the trials of three conditions of splinting, his pain was minimal. With no splint, he had pain with grip on the Visual Analog Scale at $1.50 \mathrm{~cm}$., palmar pinch at $1.60 \mathrm{~cm}$. and turning a key at $1.00 \mathrm{~cm}$.. With the short splint he had no pain except in the subtest for writing at $0.80 \mathrm{~cm}$. With the long splint, he experienced no pain in any of the activities (Figure 13). He did not complain of any other pain in other areas of his extremity during the splinted tests (see Appendix D).

\section{Function}

Subject B's Jebsen Hand Function scores are identified in Table 2. In the comparison of function, Subject B was also within the normative range of the Jebsen Hand Function Test (Jebsen, 1969) for the no splint, short splint and long splint in six 
Subject B: Relationship of Pain Scores and Activities for the Three Conditions of Splinting

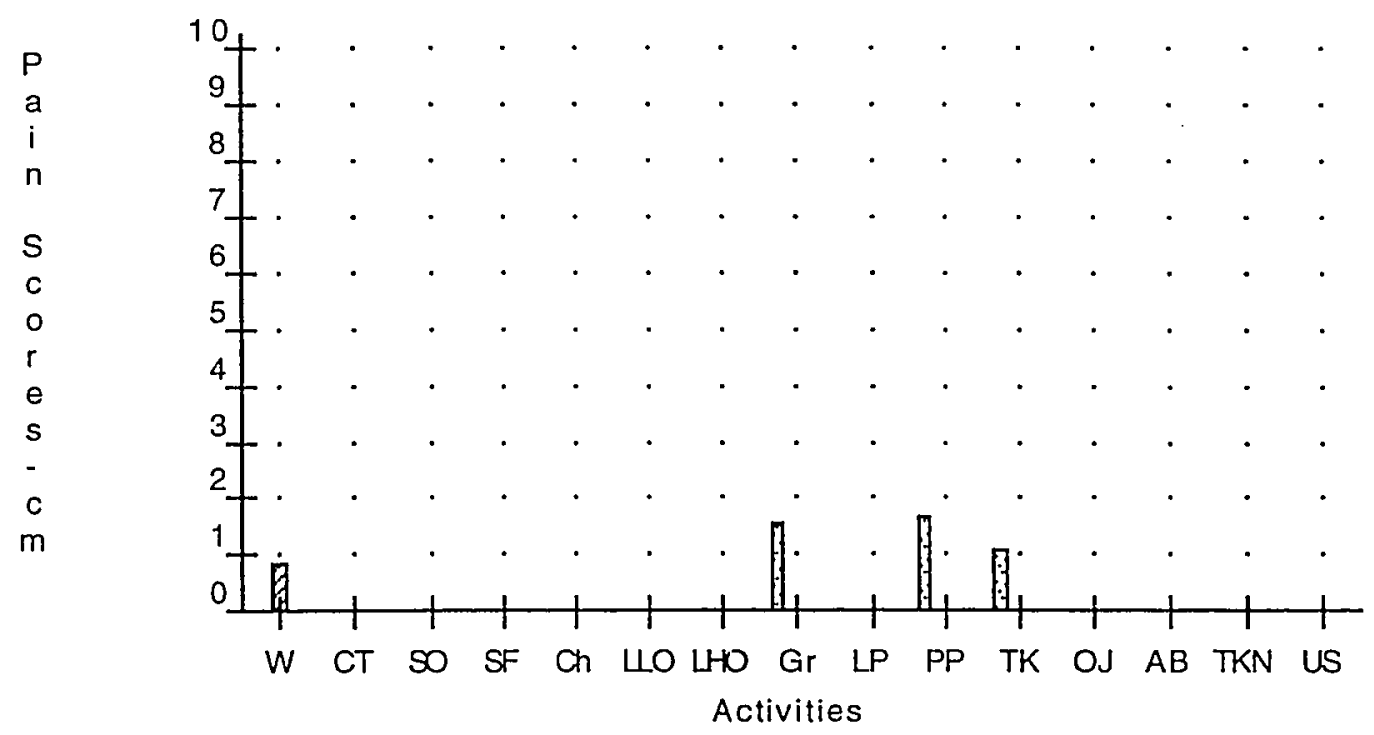

母NO SPLINT 囚SHORT SPLINT छLONG SPLINT

Legend:

$\begin{array}{ll}\text { W - Writing } & \text { LP - Lateral pinch } \\ \text { CT - Card turning } & \text { PP - Palmar pinch } \\ \text { SO - Small objects } & \text { TK - Turn key } \\ \text { SF - Simulated feeding } & \text { OJ - Open jar } \\ \text { CH - Checkers } & \text { AB - Aspirin Bottle } \\ \text { LL - Large light objects } & \text { TKN - Turn knob } \\ \text { LH - Large heavy objects } & \text { US - Use scissors } \\ \text { GR - Grip } & \end{array}$

Figure 13. Subject B: Pain Scores for All Activities for the Right Hand 
Table 2

Subject B: Jebsen Hand Function Scores in Seconds for the Three Conditions of Splinting

\begin{tabular}{lccc}
\hline Jebsen Subtest & No Splint & Short Splint & Long Splint \\
\hline Writing & $16.00 \mathrm{sec}$. & $13.00 \mathrm{sec}$. & $13.00 \mathrm{sec}$. \\
Card turning & $4.00 \mathrm{sec}$. & $4.00 \mathrm{sec}$. & $4.00 \mathrm{sec}$. \\
Small objects & $6.50 \mathrm{sec}$. & $8.00 \mathrm{sec}$. & $7.50 \mathrm{sec}$. \\
Feeding & $9.00 \mathrm{sec}$. & $10.00 \mathrm{sec}$. & $8.00 \mathrm{sec}$. \\
Checkers & $4.50 \mathrm{sec}$. & $4.50 \mathrm{sec}$. & $4.50 \mathrm{sec}$. \\
Large light objects & $4.00 \mathrm{sec}$. & $3.50 \mathrm{sec}$. & $4.00 \mathrm{sec}$. \\
Large heavy objects & $4.00 \mathrm{sec}$. & $3.50 \mathrm{sec}$. & $3.00 \mathrm{sec}$. \\
\hline
\end{tabular}


of the seven subtests. However, he was out of the normative range for the simulated feeding subtest for all three conditions. The non-splinted condition at 9 seconds took more time than the long splint condition at 8 seconds. The short splint took 10 seconds. His writing time also increased with splints. His time improved with each trial in three activities, writing, simulated feeding, and picking up large heavy objects. Grip strength increased 18 pounds with the short splint over his non-splinted condition and decreased 16 pounds with the long splint (Figure 14). He had no significant change in pinch and was able to perform all the CMC hand function activities.

\section{General Observations}

Subject B performed better with repeated trials with time scores regardless of the splints, and perceived pain was reduced during the activity with splints. He also was observed using additional elbow and shoulder movements to compensate for the splinted wrist in the long splint. He was not on anti-inflammatory medication.

\section{CaseC}

\section{Demographics}

Subject $C$ is a 69 year old, right handed retired, man who was diagnosed with right thumb CMC arthritis and referred for splinting. His diagnosis was confirmed with $X$ rays with narrowing of joint spaces of the metacarpal trapezium with bony degeneration and evidence of scaphoid trapezium degeneration. The speculation from his $\mathrm{X}$-rays was that he had "pan arthritis" or the Eaton-Littler classification IV (Eaton, et al., 1984), where the joint spaces have narrowed and many surfaces of the carpal bones were involved. He was splinted and tested in two sessions on separate days.

Pain

Subject C's left non-dominant hand was also tested. He experienced pain in his thumb during simulated feeding $(.50 \mathrm{~cm}$.$) , opening a wide mouth jar (.30 \mathrm{~cm}$.$) and$ turning a door knob $(.80 \mathrm{~cm}$.). 
Subject B: Relationship of Grip and Pinch for the Three Conditions of Splinting as Measured by Pounds of Force

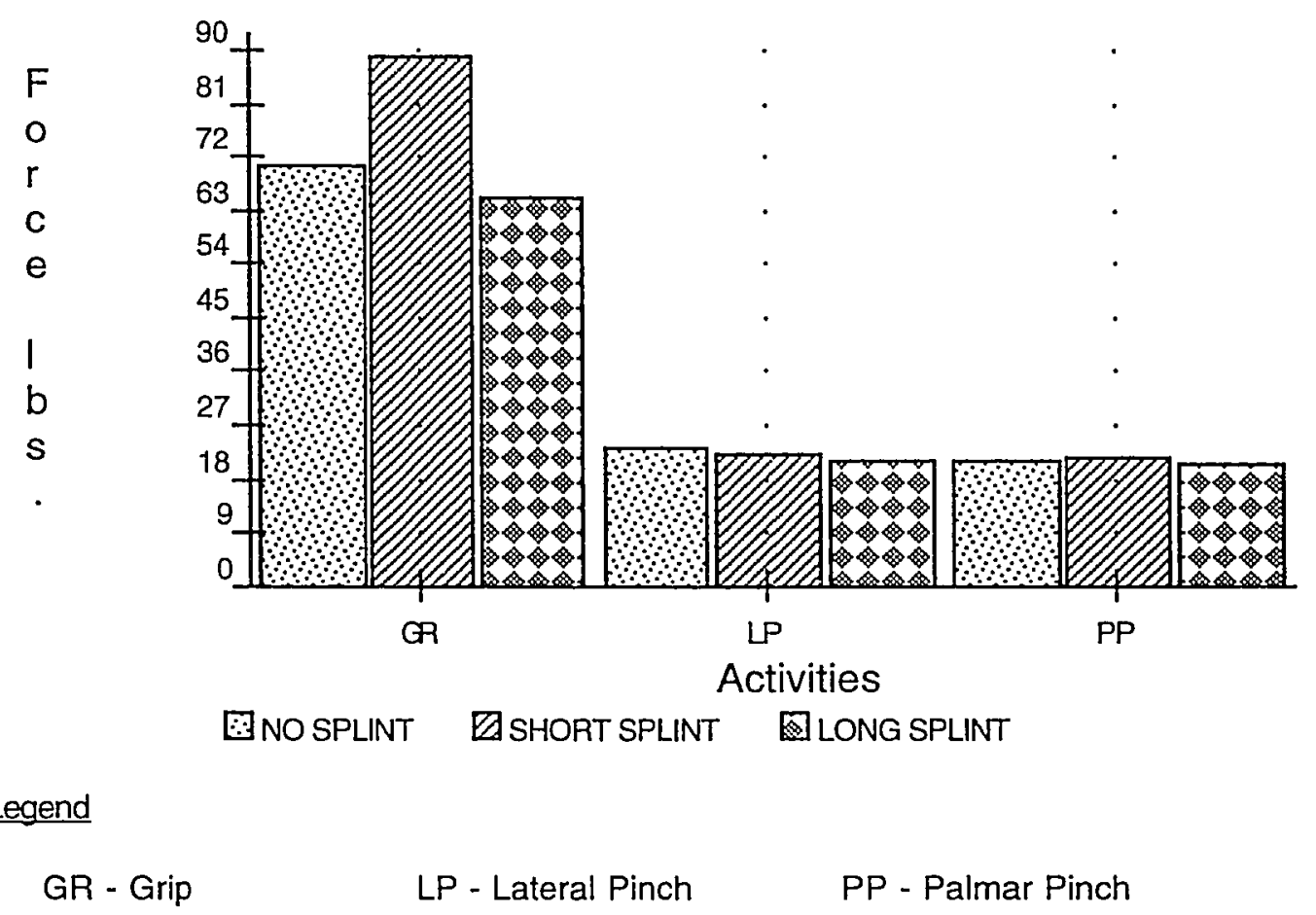

Figure 14. Subject B: Grip, Lateral Pinch and Palmar Pinch Scores for the Right Hand. 
In the no splint condition he experienced pain in his right thumb with grip ( 4.75 $\mathrm{cm}$.), lateral $(2.50 \mathrm{~cm}$.) and palmar pinch $(1.50 \mathrm{~cm}$.), picking up large heavy objects $(.70 \mathrm{~cm}$.$) , turning a key (1.00 \mathrm{~cm}$.$) , opening a jar (1.30 \mathrm{~cm}$.$) , opening an aspirin$ bottle $(1.20 \mathrm{~cm}$.$) and turning a door knob (6.20 \mathrm{~cm}$.$) . In the short and long splint he$ had pain in turning the door knob $(6.00 \& 7.00 \mathrm{~cm}$.) and opening wide mouth jar (.30 and $.80 \mathrm{~cm}$.$) . In the short splint, he had pain with large heavy objects (0.70 \mathrm{~cm}$.$) , grip$ $(.50 \mathrm{~cm}$.$) , and opening the jar (0.30 \mathrm{~cm}$.$) . With the long splint, he had pain (0.50$ $\mathrm{cm}$.), during the palmar pinch test. With no splint, short splint and long splint, he experienced pain in his left thumb when he was opening the jar (see Figure 15). During the short splint procedure, he experienced slight pain in the wrist, and with the long splint procedure he felt pain in the forearm near the lateral epicondyle.

In comparing activities with no splint and with splints, Subject $C$ became less efficient with the short and long splint. The finding shows that the long splint is less efficient than the short splint. For his age, Subject $\mathrm{C}$ scored outside the normative range for time in the unsplinted condition in 5 of the 7 Jebsen subtests (Jebsen, 1969) (Table 3). With splints he performed outside the normative range of all subtests.

In comparing grip and pinch measurements, splints increased grip and maintained pinch measurements scores (Figure 16). He was able to perform all the CMC hand function tests (Appendix E).

\section{General Observations}

In performing the task of opening the jar, Subject $C$ experienced pain in his left non-affected hand in the area of the CMC joint. In this bilateral hand activity, both hands were equally challenged. He also compensated with shoulder and elbow movements when his wrist was splinted. It was also noted that in turning the door knob, pain was more pronounced as he turned the door knob toward the thumb, rather than away from the thumb regardless of whether he was splinted. 
SUBJECT C: Relationship of Pain Scores and Activities for the

Three Conditions of Splinting

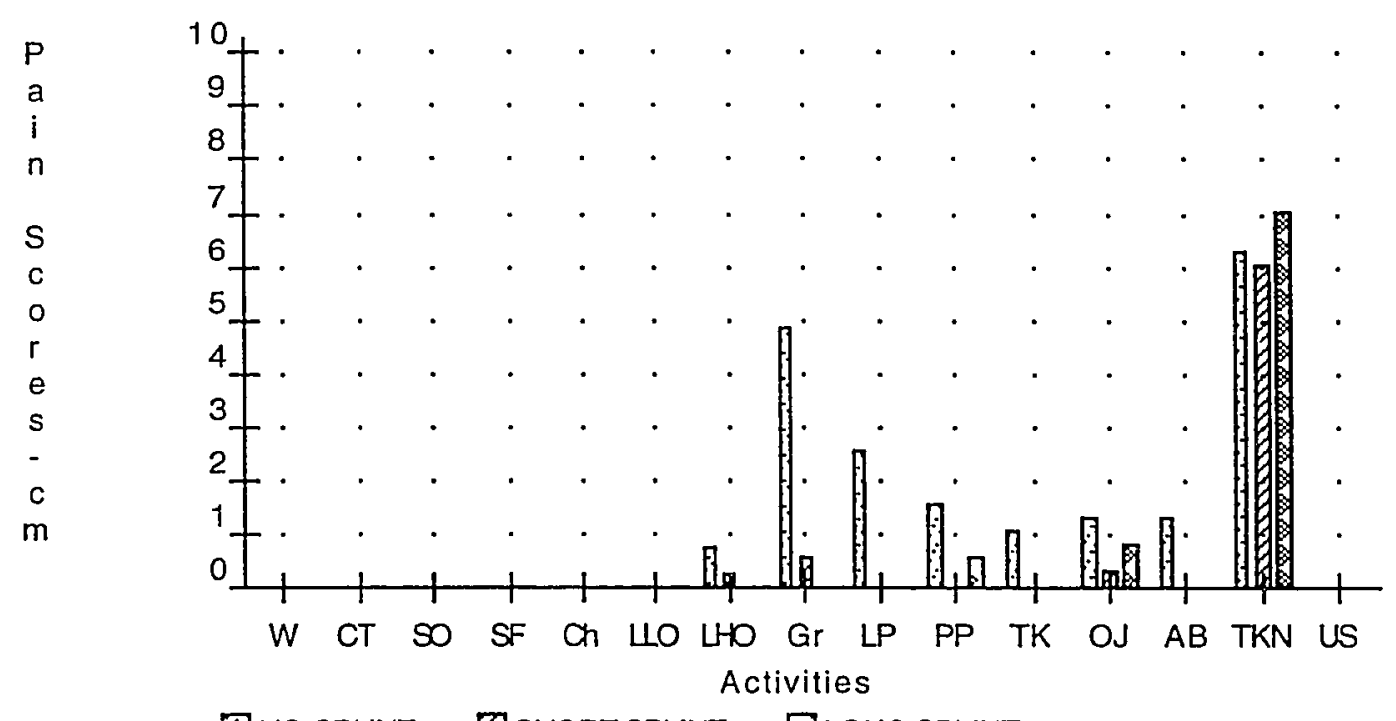

BNO SPLINT $\triangle$ SHORTSPLINT BLONGSPLINT

Legend:

$\begin{array}{ll}\text { W - Writing } & \text { LP - Lateral pinch } \\ \text { CT - Card turning } & \text { PP - Palar pinch } \\ \text { SO - Small objects } & \text { TK - Turn key } \\ \text { SF - Simulated feeding } & \text { OJ - Open jar } \\ \text { CH- Checkers } & \text { AB-Asprin Bottle } \\ \text { LL- Large light objects } & \text { TKN- Turn knob } \\ \text { LH-Large heavy objects } & \text { US- Use scissors } \\ \text { GR- Grip } & \end{array}$

Figure 15. Subject C: Pain Scores for All Activities for the Right Hand. 
Table 3

Subject C: Jebsen Hand Function Scores in Seconds for the Three Conditions of Splinting

\begin{tabular}{lrcc}
\hline Jebsen Subtest & No Splint & Short Splint & Long Splint \\
\hline Writing & $16.00 \mathrm{sec}$. & $17.00 \mathrm{sec}$. & $17.50 \mathrm{sec}$. \\
Card Turning & $4.50 \mathrm{sec}$. & $6.00 \mathrm{sec}$. & $7.25 \mathrm{sec}$. \\
Small objects & $13.00 \mathrm{sec}$. & $16.00 \mathrm{sec}$. & $16.00 \mathrm{sec}$. \\
Feeding & $11.00 \mathrm{sec}$. & $12.00 \mathrm{sec}$. & $13.00 \mathrm{sec}$. \\
Checkers & $5.00 \mathrm{sec}$. & $6.00 \mathrm{sec}$. & $6.25 \mathrm{sec}$. \\
Large light objects & $4.75 \mathrm{sec}$. & $4.75 \mathrm{sec}$. & $6.25 \mathrm{sec}$. \\
Large heavy objects & $4.75 \mathrm{sec}$. & $5.75 \mathrm{sec}$. & $6.75 \mathrm{sec}$. \\
\hline
\end{tabular}


SUBJECT C: Relationship of Grip and Pinch for the Three Conditions of Splinting as Measured by Pounds of Force

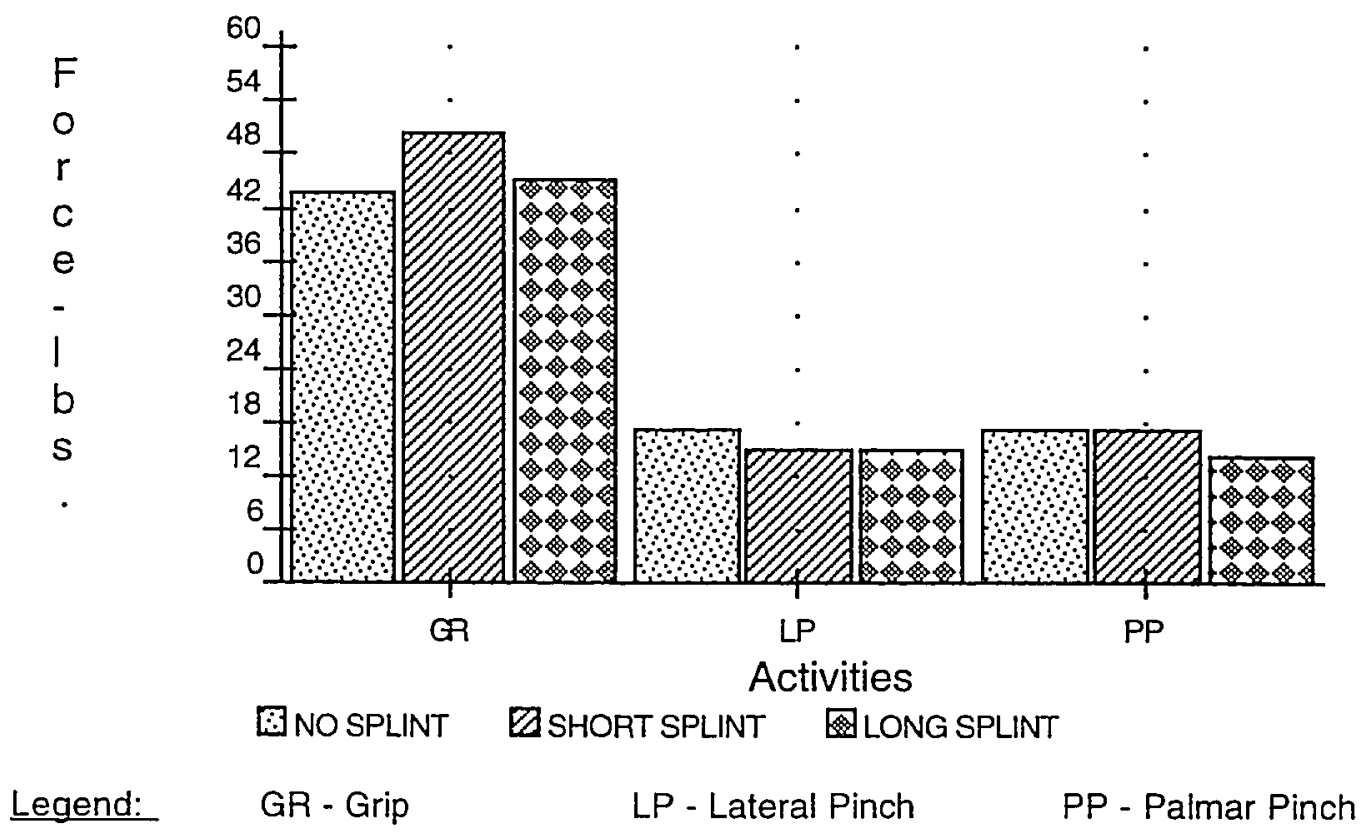

Figure 16. Subject C: Grip, Lateral Pinch and Palmar Pinch Scores for the Right Hand. 


\section{Case D}

\section{Demographics}

Subject $D$ is a 64 year old, retired, right handed man who was referred to hand therapy with clinical and X-ray confirmation of severe thumb CMC arthritis for his left hand. His avocations were woodworking and playing the accordion, which were painful and difficult activities. He was splinted and tested in one session. His left, non-involved hand had no pain during the test.

Pain

In the trials with his right hand, Subject $D$ experienced severe pain with several activities. In the no splint procedure, he had pain in writing $(1.00 \mathrm{~cm}$.$) , with large$ heavy objects $(0.70 \mathrm{~cm}$.$) , grip (2.50 \mathrm{~cm}$.$) , opening the aspirin bottle (1.10 \mathrm{~cm}$.$) ,$ turning door knob $(8.30 \mathrm{~cm}$.), using scissors $(1.20 \mathrm{~cm}$.). In lateral pinch, palmar pinch and turning a key, he rated his pain at $10.00 \mathrm{~cm}$. In the short splint trial, he rated his pain with card turning $(0.90 \mathrm{~cm}$.), small objects $(.30)$, palmar pinch $(8.90$ $\mathrm{cm}$.$) , turning a key (8.60 \mathrm{~cm}$.$) , opening an aspirin bottle (1.40 \mathrm{~cm}$.$) , large heavy$ objects, grip, lateral pinch and using scissors at $10 \mathrm{~cm}$. (CMC data sheet, Appendix F).

With the long splint trial, he experienced pain with small objects $(0.40 \mathrm{~cm}$.), large light, large heavy objects and turning a key $(1.40 \mathrm{~cm}$.), and opening an aspirin bottle $(0.40 \mathrm{~cm}$.) Activities which created pain to the $10 \mathrm{~cm}$. pain level with the short splint were not repeated with the long splint. These activities were grip, lateral pinch, palmar pinch and use of the scissors $(10 \mathrm{~cm}$.) (Figure 17).

\section{Function}

In the Jebsen Hand Function Test (Jebsen, 1969), Subject D's time scores were within the normative range for all the subtests except the checkers and small objects subtest with no splint (see Table 4). With the short and long splint, he was out of the 
SUBJECT D: Relationship of Pain Scores and Activities for the Three Conditions of Splinting

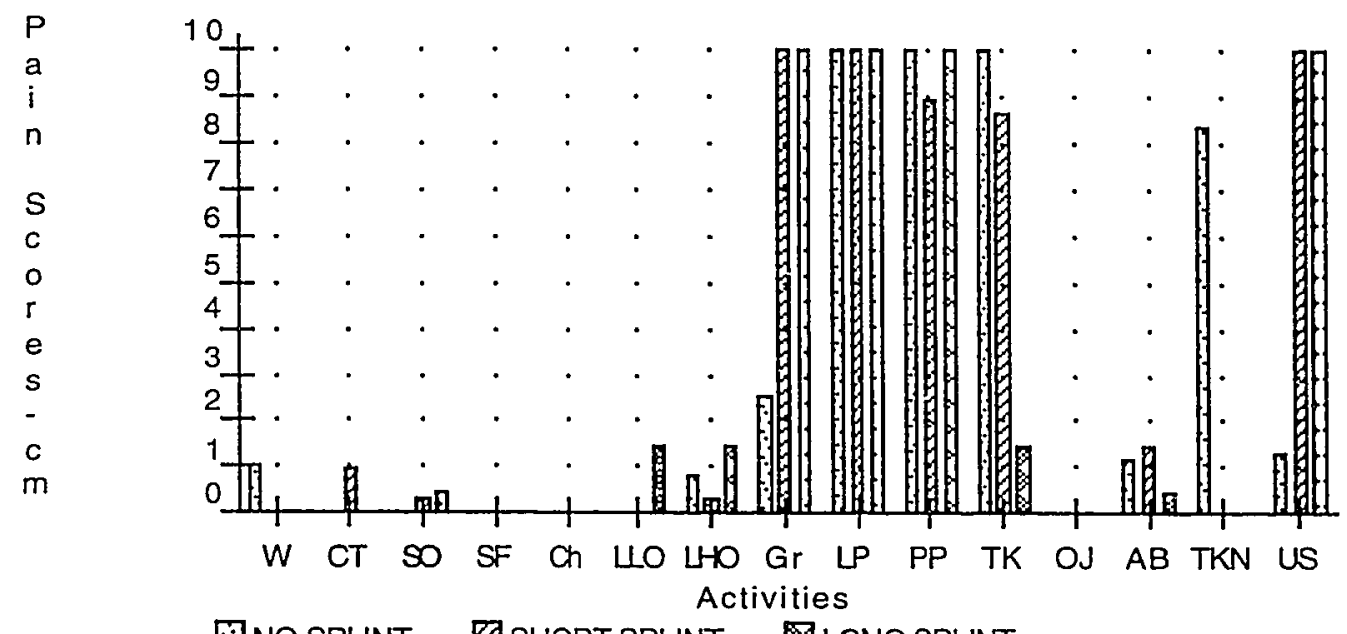

BNO SPLINT ZSHORT SPLINT QLONGSPLINT

Legend:

$\begin{array}{ll}\text { W - Writing } & \text { LP - Lateral pinch } \\ \text { CT - Card turning } & \text { PP - Palar pinch } \\ \text { SO - Small objects } & \text { TK - Turn key } \\ \text { SF - Simulated feeding } & \text { OJ - Open jar } \\ \text { CH - Checkers } & \text { AB - Asprin Bottle } \\ \text { LL- Large light objects } & \text { TKN - Turn knob } \\ \text { LH - Large heavy objects } & \text { US - Use scissors } \\ \text { GR- Grip } & \end{array}$

Figure17. Subject D: Pain Score for All Activities for the Left Hand 
Table 4

Subject D: Jebsen Hand Function Scores in Seconds for the Three Conditions of Splinting

\begin{tabular}{lrcc}
\hline Jebsen Subtest & No Splint & Short Splint & Long Splint \\
\hline Writing & $30.50 \mathrm{sec}$. & $44.00 \mathrm{sec}$. & $30.00 \mathrm{sec}$. \\
Card Turning & $4.00 \mathrm{sec}$. & $6.50 \mathrm{sec}$. & $5.25 \mathrm{sec}$. \\
Small objects & $10.00 \mathrm{sec}$. & $11.00 \mathrm{sec}$. & $14.00 \mathrm{sec}$. \\
Feeding & $7.00 \mathrm{sec}$. & $8.00 \mathrm{sec}$. & $8.75 \mathrm{sec}$. \\
Checkers & $6.25 \mathrm{sec}$. & $5.00 \mathrm{sec}$. & $5.25 \mathrm{sec}$. \\
Large light objects & $4.00 \mathrm{sec}$. & $4.25 \mathrm{sec}$. & $3.50 \mathrm{sec}$. \\
Large heavy objects & $4.00 \mathrm{sec}$. & $4.00 \mathrm{sec}$. & $4.00 \mathrm{sec}$. \\
\hline
\end{tabular}


normative range for writing, picking up small objects, simulated feeding and stacking checkers. With the long splint, he improved with writing and picking up large light objects. He appeared to get better with each trial.

With the long splint, he substituted motion at the elbow and shoulders for limited wrist movements. He was unable to repeat the grip and pinch test. He was unable to use the scissors with splints due to severe pain. The last trial with the long splint with resistive activities was not repeated, since he was painful on the second trial to the 10 $\mathrm{cm}$. scale. Instead of a 0 rating for the unrepeated trial, the no splint score was used in the CMC data sheet (see Figure 18).

\section{General Observation}

Subject $D$ was less efficient in picking up small objects, large light and large heavy objects. These activities were also subtests in which the splints did not help his pain. His pain was greatest in tasks that provided resistance to the thumb, such as, grip, pinch, turning key, turning door knob, using scissors, and opening an aspirin bottle. In the unsplinted condition he stated that he normally used his index and long finger to turn a key. His pain escalated once the activity was performed that aggravated his pain. He was not on any anti-inflammatory medications. He was splinted to protect his thumb during activities and to decrease pain until surgery. Activities that were painful were not repeated.

\section{CaseE}

\section{Demographics}

Subject $E$ is a 73 year old, retired, right handed woman who was referred from Hand Clinic with a diagnosis of left thumb carpometacarpal arthritis. Diagnosis was confirmed by $\mathrm{X}$-rays. Subject $\mathrm{E}$ volunteers for various veteran organizations and is an active woman. A left CMC hand based splint was constructed and tested in two separate sessions. 
SUBJECT D: Relationship of Grip and Pinch for the Three Conditions of Splinting as Measured by Pounds of Force

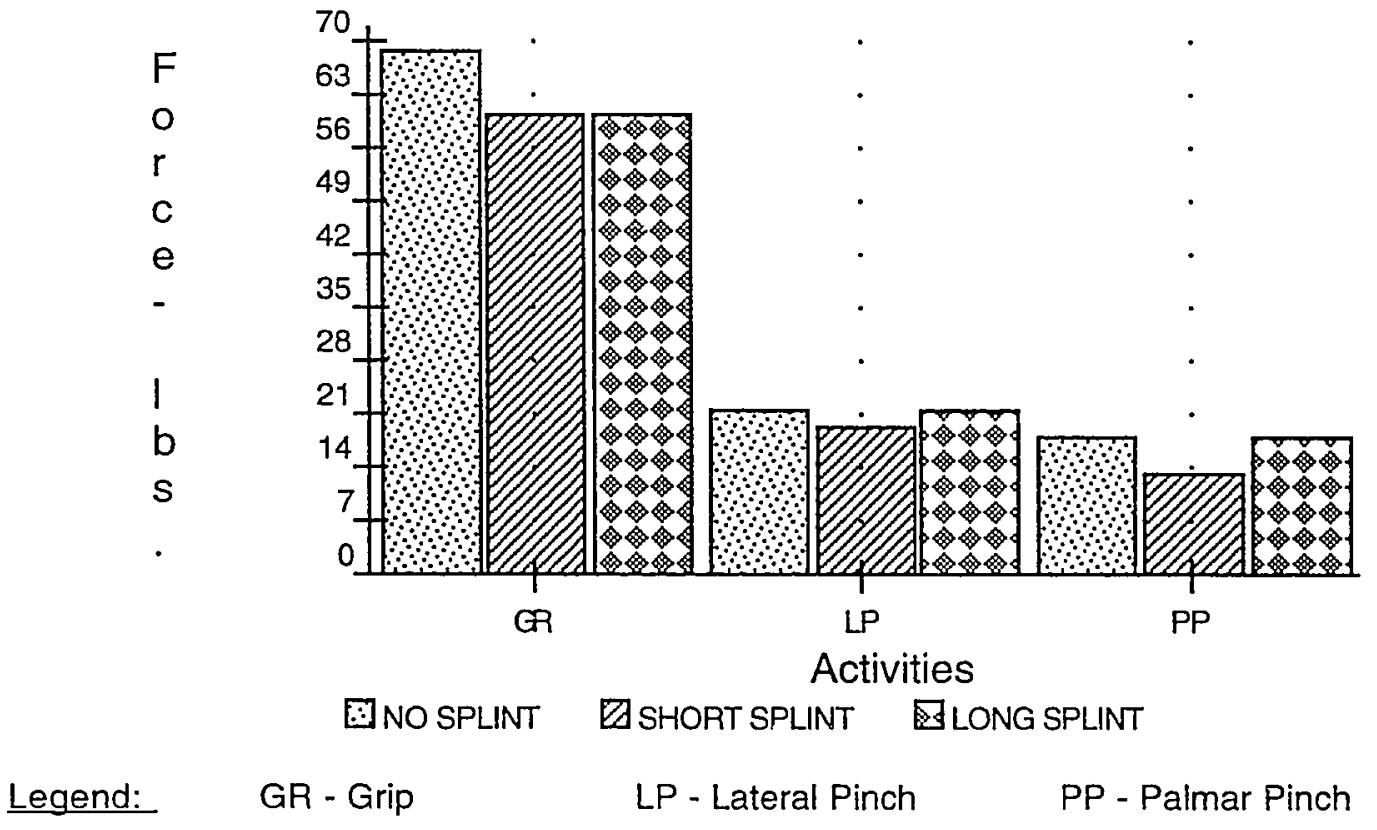

Figure 18. Subject D: Grip, Lateral Pinch and Palmar Pinch Scores for the Right Hand. 
Pain

Subject E's right hand is her non-involved hand and she reported no pain in any of the functional activities. Her unsplinted left hand had pain with functional activities. Her pain was greatest in grip $(3.5 \mathrm{~cm})$, opening a jar $(2.5 \mathrm{~cm}$.), using scissors $(2.4$ $\mathrm{cm}$.) and lateral pinch $(0.9 \mathrm{~cm}$.). She did not complete the activity which required use of scissors $(10 \mathrm{~cm}$.$) .$

With the short splint, pain was diminished in all of the previous activities, but pain occurred in turning a door knob $(2.1 \mathrm{~cm}$.). She completed the activity with the scissors using the splints with no pain. With the long splint, she had no pain in any activity except turning the door knob $(1.30 \mathrm{~cm}$.)(Figure 19). Her pain in this activity could have been be due to the direction she was turning door knob during the trials. During the no splint trial, she had no pain; however, during the splinted trials, she had noticeable pain. In exploring the activity and pain relationship, the direction of turning the door knob did make a difference for Subject E. Pain was increased turning toward the thumb and eliminated turning away from the thumb (Appendix $G$ ).

\section{Function}

Data for Subject $E$ for the Jebsen Hand Function Test are presented in Table 5. For her age and non-dominant hand, she was in the Jebsen Hand Function Test (Jebsen, 1969) normative range for all subtests except for small objects and large heavy objects in the unsplinted condition. This was also the case for the short splint, except in this trial, the large light objects fell outside of normative range. In the long splint trial, she became more inefficient and writing was the only score in the normative range.

Subject $E$ performed best with grip testing in the no splint condition. Grip decreased 12 pounds in both the short and long splint condition. Lateral and palmar pinch scores did not change significantly with the splints (Figure 20). However, she 
SUBJECT E: Relationship of Pain Scores and Activities for the Three Conditions of Splinting.

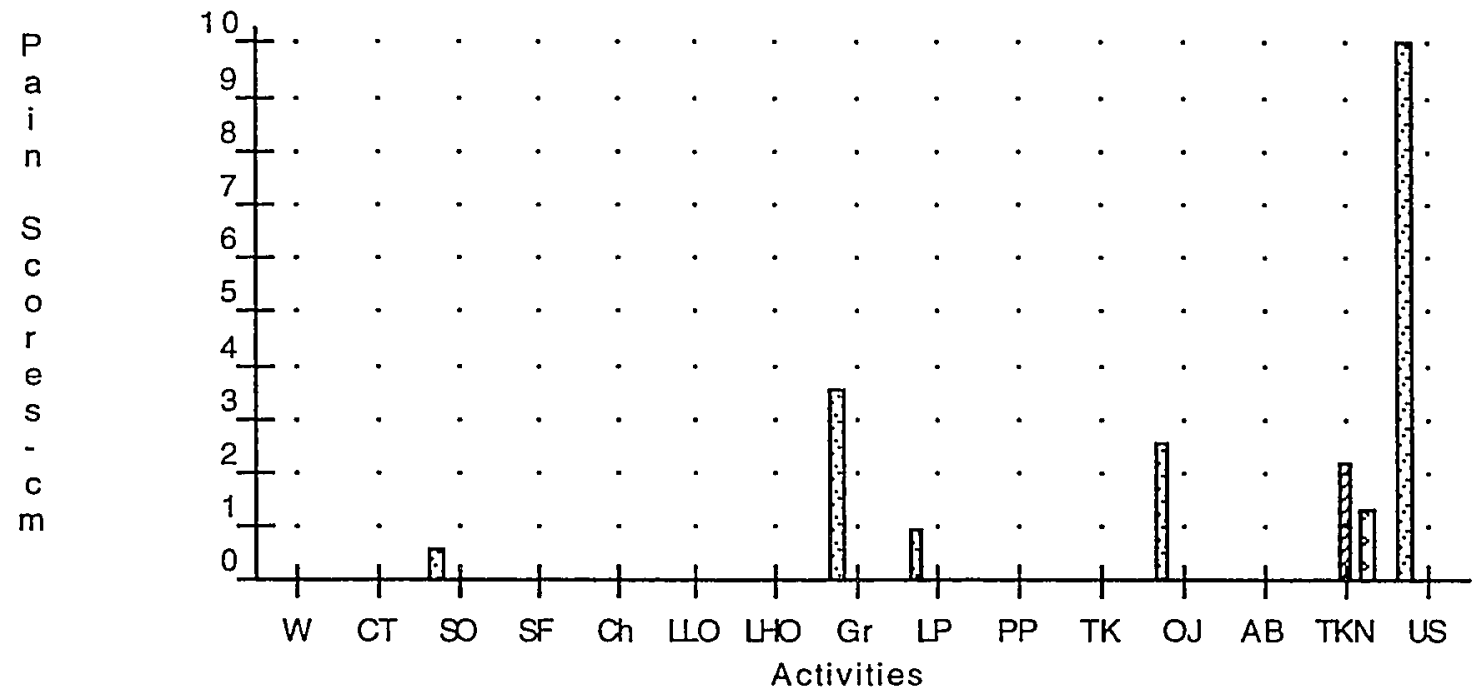

ĐNOSPLINT ZSHORT SPLINT 因LONG SPLINT

Legend:

$\begin{array}{ll}\text { W - Writing } & \text { LP - Lateral pinch } \\ \text { CT - Card turning } & \text { PP - Palar pinch } \\ \text { SO - Small objects } & \text { TK - Turn key } \\ \text { SF - Simulated feeding } & \text { OJ - Open jar } \\ \text { CH - Checkers } & \text { AB - Aspirin Bottle } \\ \text { LL - Large light objects } & \text { TKN - Turn knob } \\ \text { LH - Large heavy objects } & \text { US - Use scissors } \\ \text { GR - Grip } & \end{array}$

Figure 19. Subject E: Pain Scores for All Activities for the Right Hand 
Table 5

Subject E: Jebsen Hand Function Scores in Seconds for the Three Conditions of Splinting

\begin{tabular}{lrcc}
\hline Jebsen Subtest & No Splint & Short Splint & Long Splint \\
\hline Writing & $19.00 \mathrm{sec}$. & $24.00 \mathrm{sec}$. & $19.00 \mathrm{sec}$. \\
Card Turning & $4.00 \mathrm{sec}$. & $4.00 \mathrm{sec}$. & $10.00 \mathrm{sec}$. \\
Small objects & $11.00 \mathrm{sec}$. & $10.00 \mathrm{sec}$. & $9.00 \mathrm{sec}$. \\
Feeding & $9.00 \mathrm{sec}$. & $9.00 \mathrm{sec}$. & $11.00 \mathrm{sec}$. \\
Checkers & $3.50 \mathrm{sec}$. & $3.50 \mathrm{sec}$. & $5.00 \mathrm{sec}$ \\
Large light objects & $4.00 \mathrm{sec}$ & $5.00 \mathrm{sec}$. & $5.50 \mathrm{sec}$. \\
Large heavy objects & $5.00 \mathrm{sec}$. & $6.00 \mathrm{sec}$. & $6.00 \mathrm{sec}$. \\
\hline
\end{tabular}


SUBJECT D: Relationship of Grip and Pinch tot the Three Conditions of Splinting as Measured by Pounds of Force

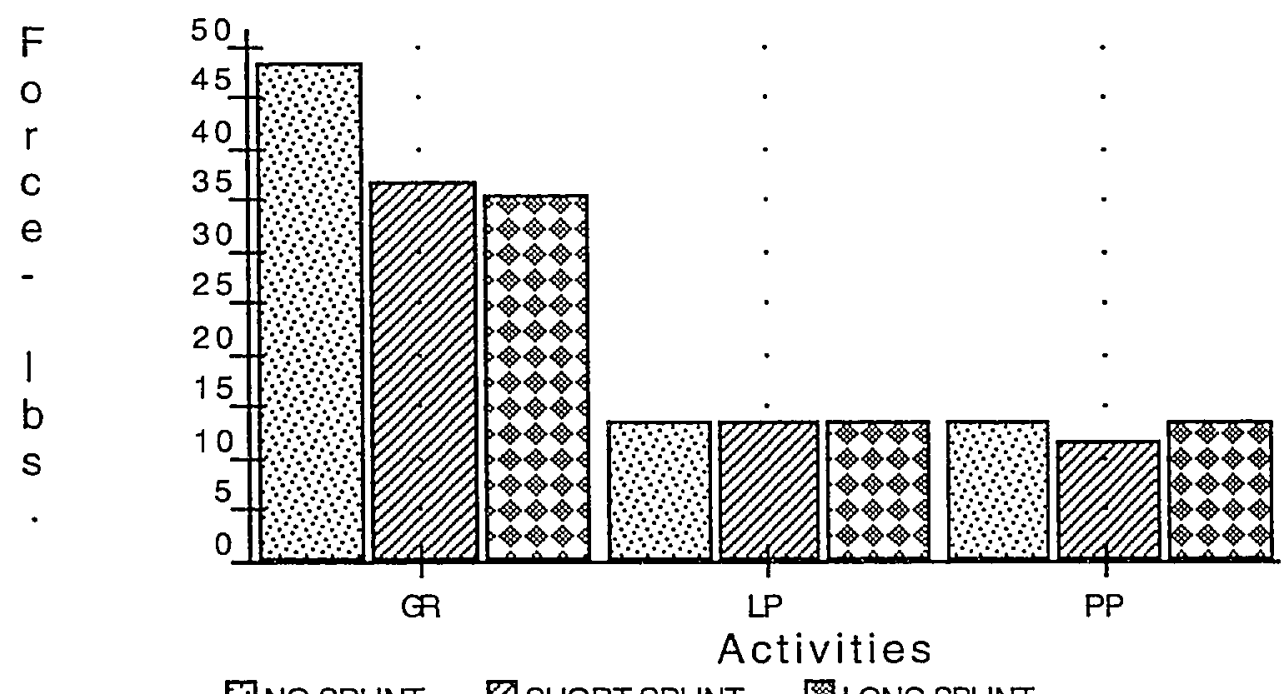

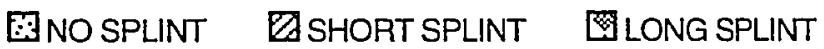

Legend: $\quad$ GR - Grip LP - Lateral Pinch PP - Palmar Pinch

Figure 20. Subject E: Grip, Lateral Pinch and Palmar Pinch Scores for the Left Hand. 
experienced pain in the no splint condition and no pain with less grip force in the splinted condition.

In the unsplinted trial, she had difficulty with the CMC hand function tests and was unable to complete the task with the scissors. With splints on, she was able to complete the activity using the scissors.

\section{General Observation}

Subject $E$ also has a number of medical conditions and was taking various medications. However, she was not on anti-inflammatory medication. She also used compensatory movement at the elbow and shoulder to perform activities using the long splint. She preferred to use only the hand-based splint and felt that her pain had decreased since she started using the splint.

\section{Results and Discussion}

The data content from five case studies were analyzed for patterns and trends that could be occurring in splinting, hand function and pain in thumb carpometacarpal arthritis in order to answer the research questions posed for this study.

\section{Research Questions Answered}

\section{Research Question One}

Question one of this research was: "What is the effect of the long wrist thumb splint and the short hand-based thumb splint on hand function and pain in patients with thumb CMC arthritis?"

Hand function. The Jebsen Hand Function Test (Jebsen, 1969), grip pinch and CMC hand function tests were analyzed separately. The components of motion that are involved with challenging the $\mathrm{CMC}$ in this study were time and force. The Jebsen Test (Jebsen 1969) is a timed test and has characteristics of general hand function activities that are performed everyday. The grip and pinch test and the CMC hand function test were activities that provided resistance to the thumb and required force to perform. The 
activities requiring force from the thumb or that provided resistance to the thumb created the most pain. The activities that created the most pain in all the subjects were charted to describe changes in function relative to pain scores for each subject (Figure $21,22,23,24,25)$.

In the Jebsen Hand Function Test (Jebsen, 1969), Subjects A, C, D and E developed patterns that indicated that the best scores occurred in the no splint condition. The short splint was second best and, and the long splint was the least efficient. In Subject B and in some parts of E's test, their performance was better with the long splint than with no splint or the short splint. This could be attributed to the repetition of the activity. However, the scores are a matter of seconds in this test and in the overall picture the subjects were still very functional.

In grip testing, Subjects $A, B$, and $C$ performed better with the short splint than with the no splint condition. The grip strength scores for Subject $D$ and $E$ decreased 10 to 12 pounds. Pinch function did not vary much in the three conditions, except in subject A. Palmar pinch was 6 pounds higher in the no splint condition. Subject D did not complete the 3 trials of grip and pinch testing due to pain.

Two subjects, Subject $D$ and Subject $E$ did not complete the scissors activity in the CMC test. Subject D was unable to complete this activity in the no splint condition due to pain. Subject $E$ was able to perform the activity using splints. The $C M C$ hand function test gave some insightful information regarding performance testing with the thumb. Opening a wide mouth jar is a bilateral hand activity that tests both hands since the resistance for opening is in opposite directions against one's own resistence. With Subjects $C$ and $E$, opening a door knob created more pain or less pain depending on the direction of turn. Subject $E$ was requested to turn the door knob counter clockwise with her left hand rather than clockwise. She had no pain in the activity. 


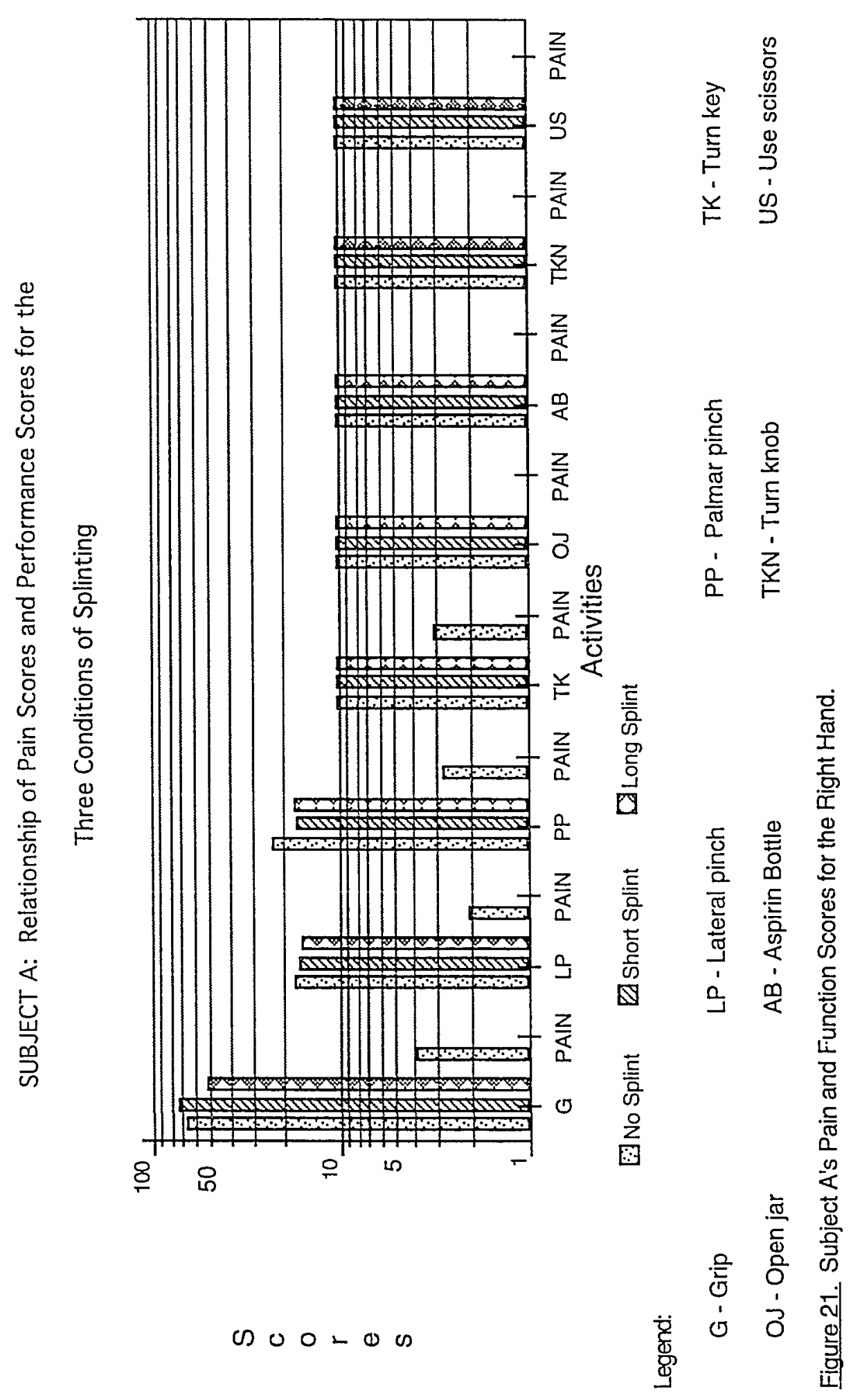



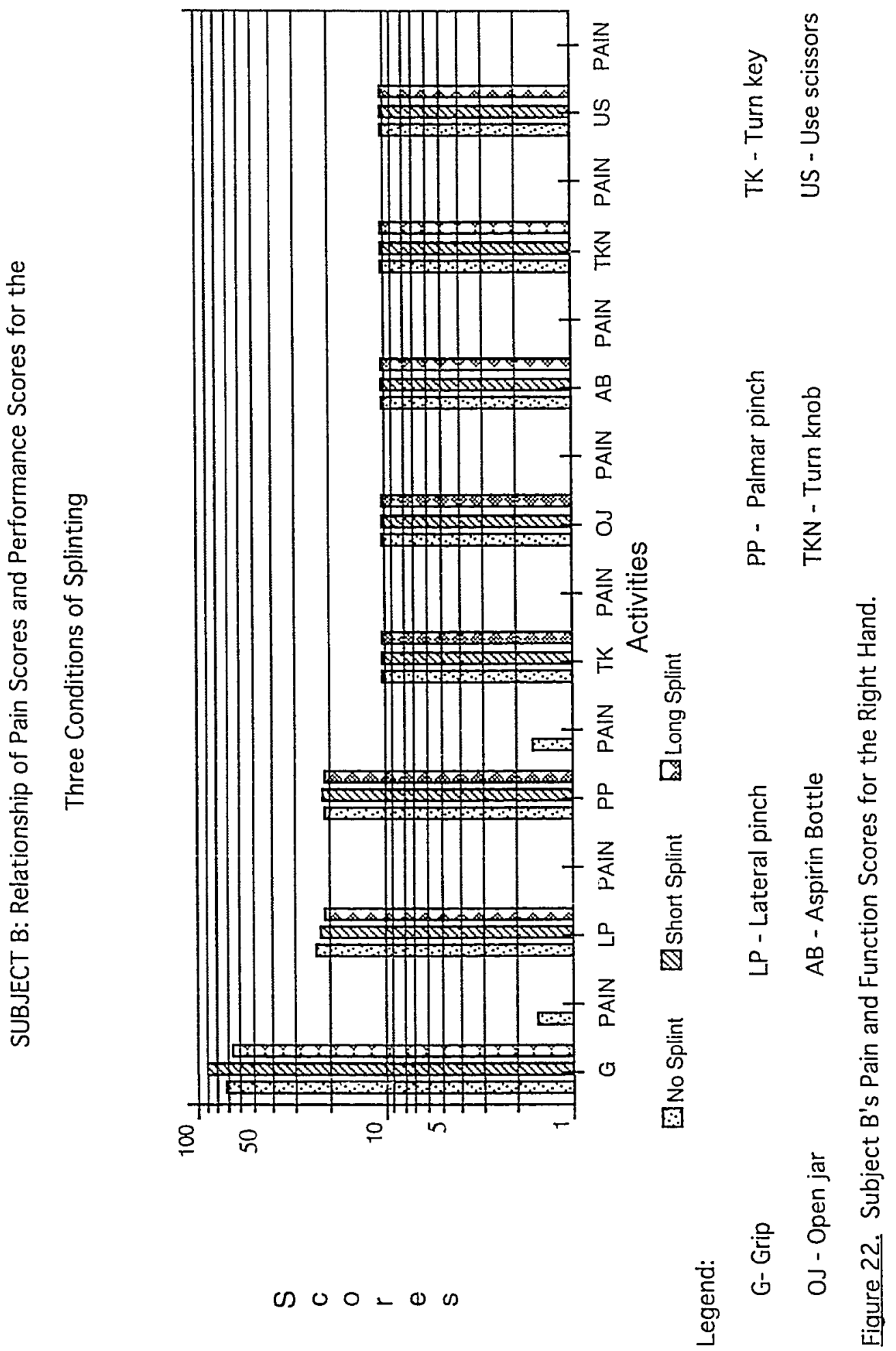


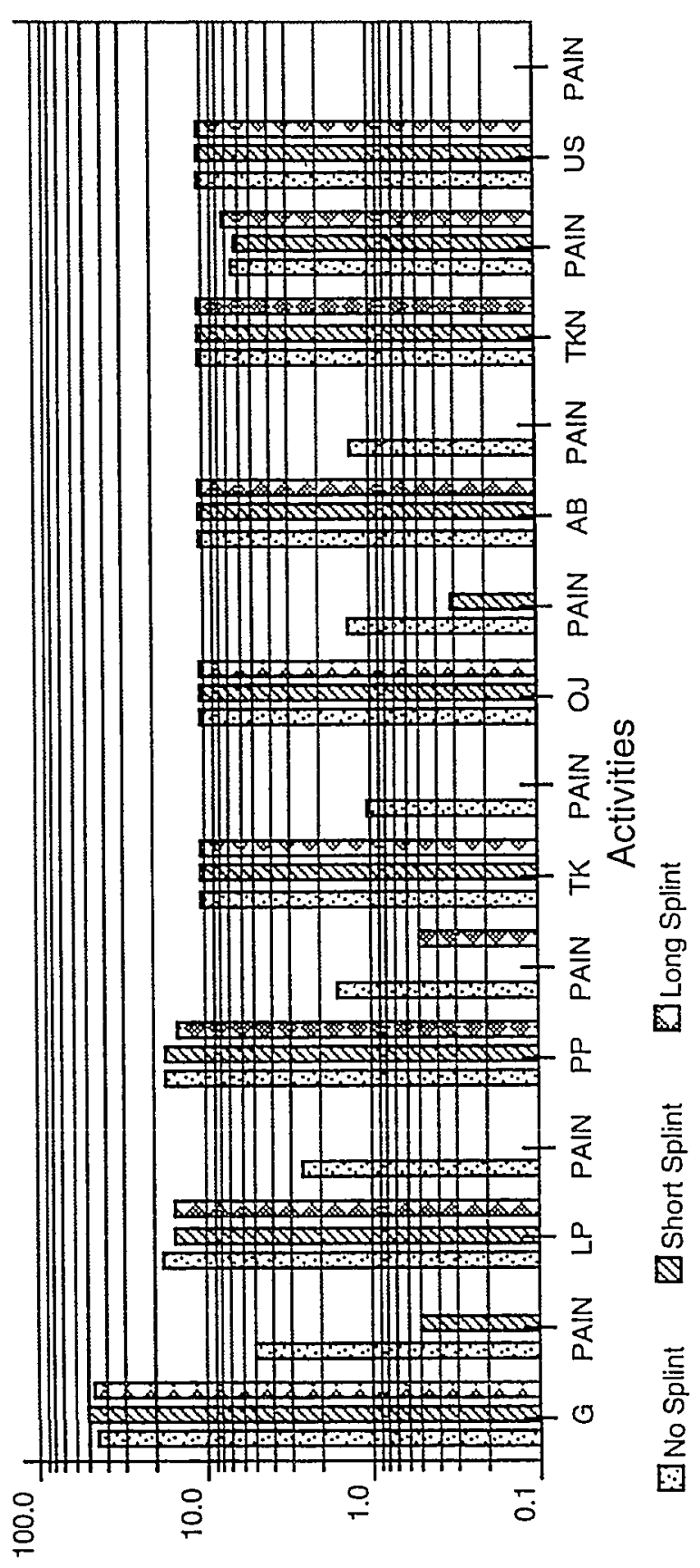

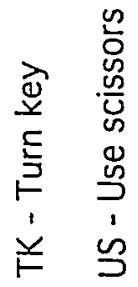

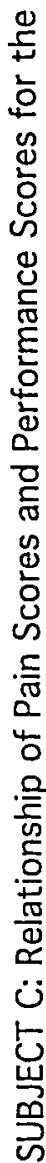

ल $00+0 \omega$

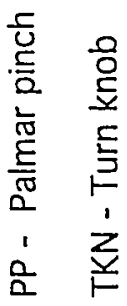

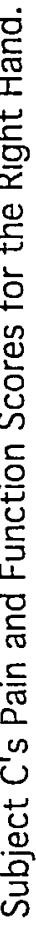

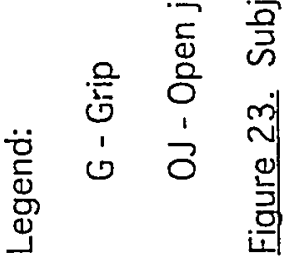




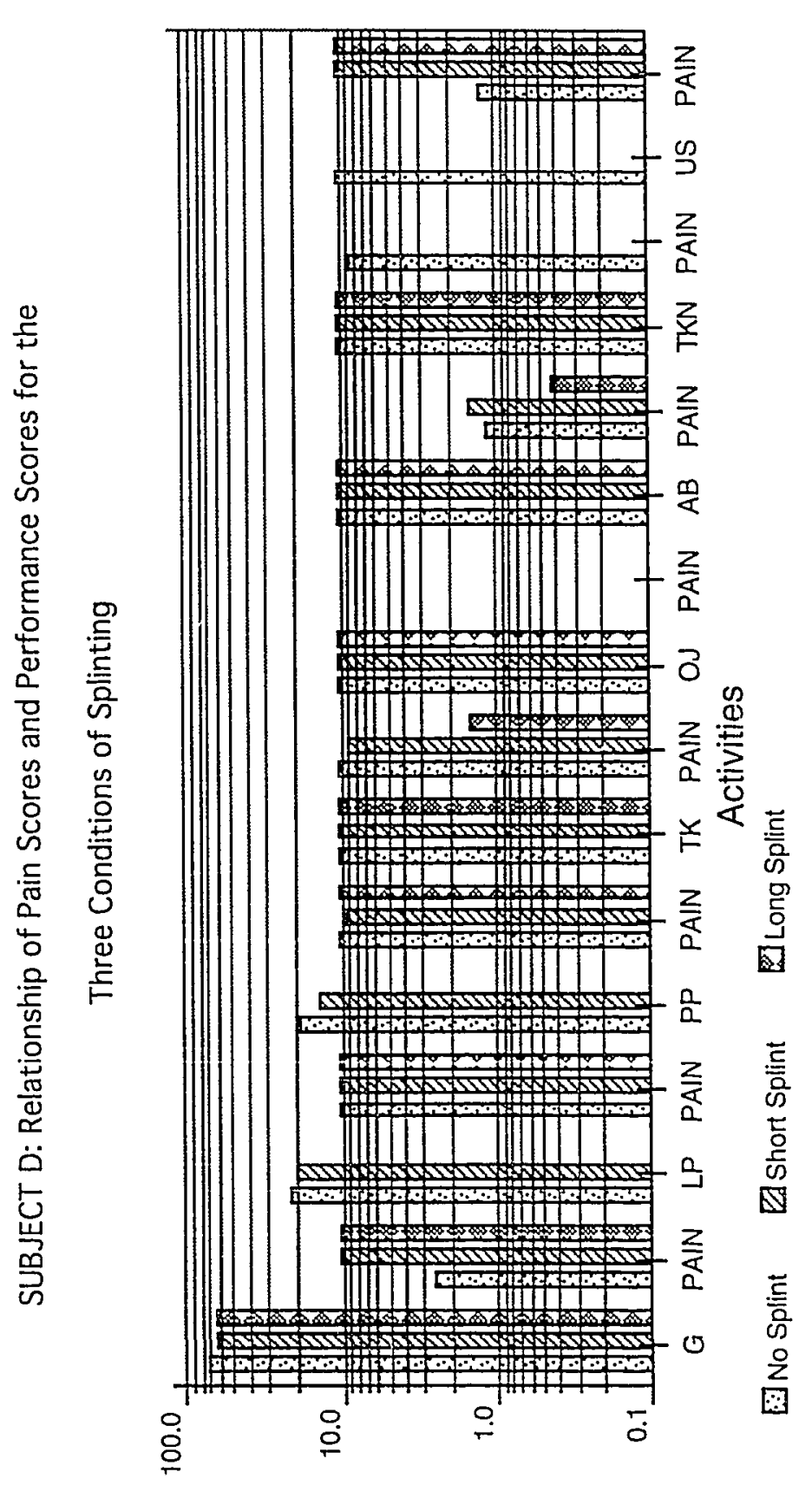

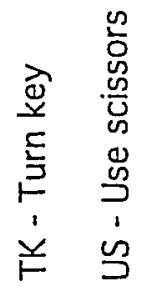

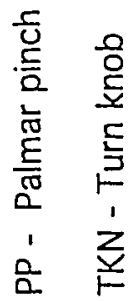

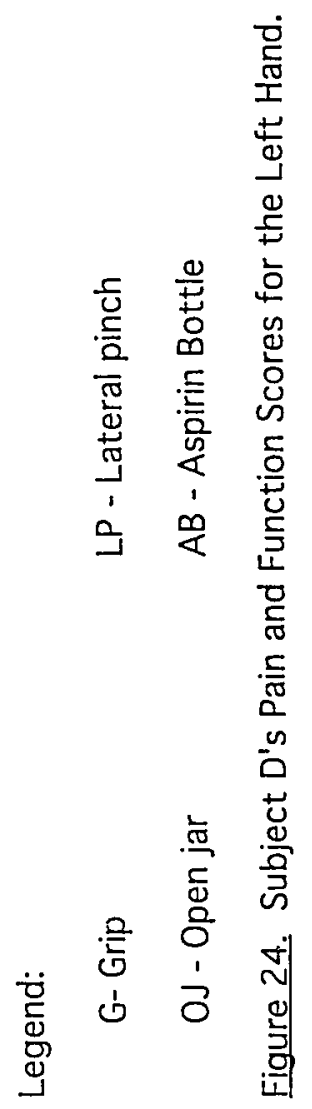




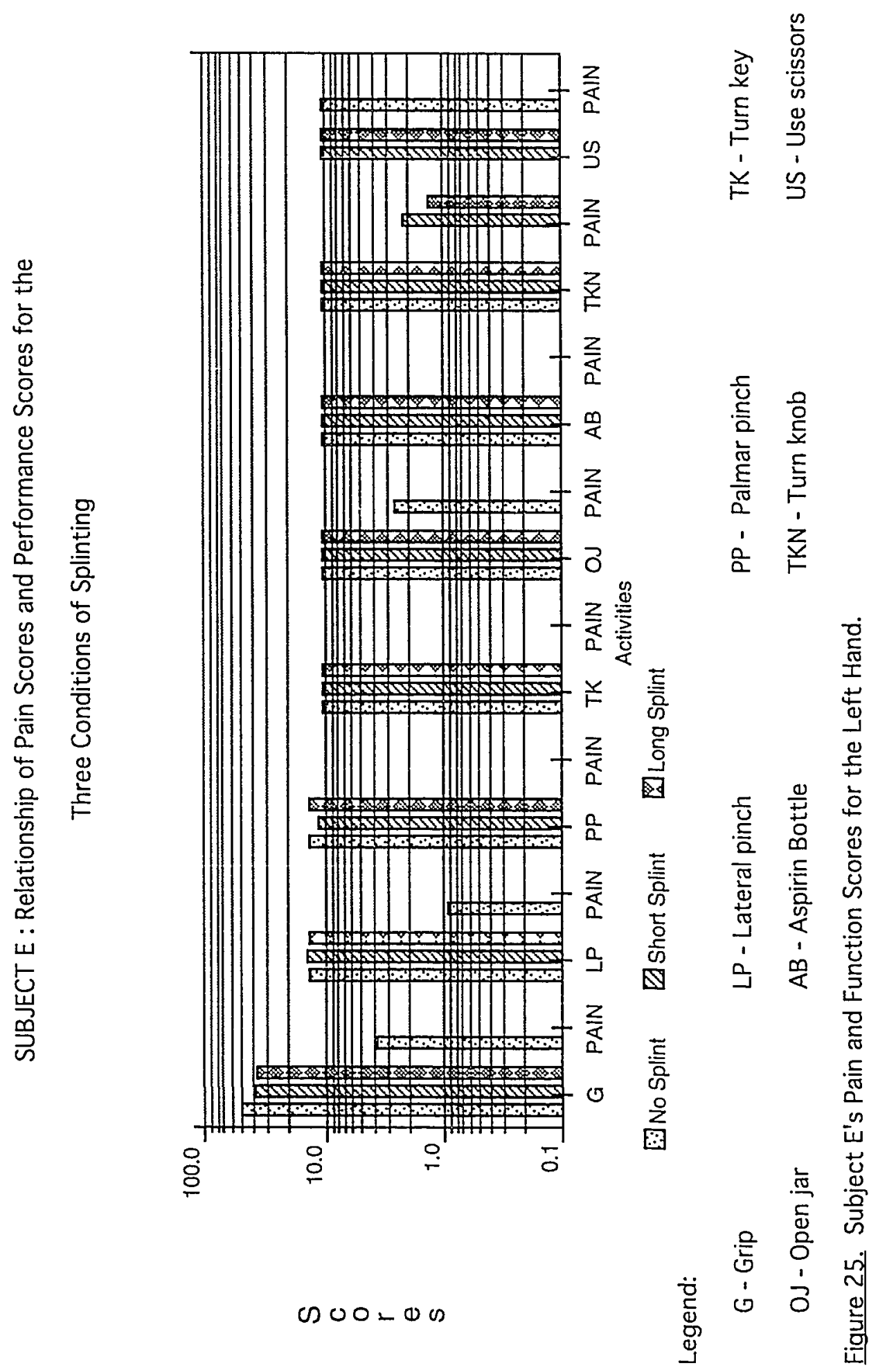


In conclusion, either the short or long splint would be effective for functional activities. Several seconds of time for an activity would still allow a person to have functional peformance. With practice all difficult activities can be performed efficiently. The short splint would probably be adequate if pain is not severe. It was observed that all subjects would increase shoulder and elbow movements when the long wrist splint was used. For prolonged periods of time the long splint may create problems elsewhere in the upper extremity due to abnormal substitution patterns.

Pain. Pain was greatest in the activities that provided resistance to the thumb and required force on behalf of the subject. In the pain comparison scales for each subject, the activities on the right half of the graph from grip, to using scissors were the most challenging. The Jebsen Hand Function Test (Jebsen, 1969) did not generate much pain greater than $3.5 \mathrm{~cm}$..

All subjects experienced pain in grip and lateral pinch testing. This was a test they all performed with reservation and were given permission to stop at any time. Subject D was unable to perform many of the resistive activities on his third trial due to pain. In the case of Subject $D$ the goals for splinting were joint position, joint protection and prevention of further pain rather than increasing function and decreasing pain. However, in his last trial, even Subject $D$ benefited from the long splint in the activity of turning a key.

The short splint seemed to be adequate to control pain if the thumb is positioned properly. Subject A benefited from the short splint, and the long splint. The long splint provided some relief to Subjects B, C and E. The logical conclusion would be that if there is less CMC damage, the shorter splint can be used. When the CMC joint is more inflamed or diseased, the longer splint may need to be used to decrease pain.

Research Question two : "What is the perceived pain relief during functional activity using the two type of splints during the activities as compared to the unsplinted thumb 
and hand during the activities?"

In order to identify perceived pain relief, the activities that created the most pain needed to be identified. The pain scores on the Visual Analog Scale were combined for each activity to identify a trend of the most painful activity to the least painful activity for the five Subjects. The activities that created the most pain had a cumulative score of 8 to $16 \mathrm{~cm}$. on the Visual Analog Scale. These activities were grip, lateral and palmar pinch testing, turning a key, turning a door knob, and using scissors (Figure 26, 27). Opening an aspirin bottle, opening a jar and the Jebsen Hand Function Test (Jebsen, 1969) had cumulative scores less than $3.5 \mathrm{~cm}$..

The short and the long splint were equally effective in reducing pain (Figure 26 ). These activities were painful even with splints. However, Subject $D$ brought up the scores on these tests. The long splint was more effective with pain relief with the activities of writing, card turning, turning a key, opening an aspirin bottle, turning a knob. The short splint was more effective in reducing pain in, picking up small objects, and large heavy objects. The activities that did not produce pain were simulated feeding and stacking checkers (see Figure 28). In the testing procedure, Subjects $A, B, C$ and $E$ felt that their pain was less with splints and their preference for splints was the short splint. Subject $D$ needed the long splint for joint protection until surgery.

The cumulative pain score on the Jebsen Hand Function Test (Jebsen, 1969) was less than 2 in any of the seven subtests. There was no perceived pain with the simulated feeding and stacking checkers subtest. The short splint and long splint each decreased pain in two subtests.

Total scores on the CMC tests compared the effects of splinting on five tasks. Pain was reduced with the long splint in 3 out of the 5 tasks. Using scissors was a difficult activity and the short splint was effective with opening the jar. 
Relationship of Cumulative Pain Scores in Grip and Pinch Testing for the Three Conditions of Splinting

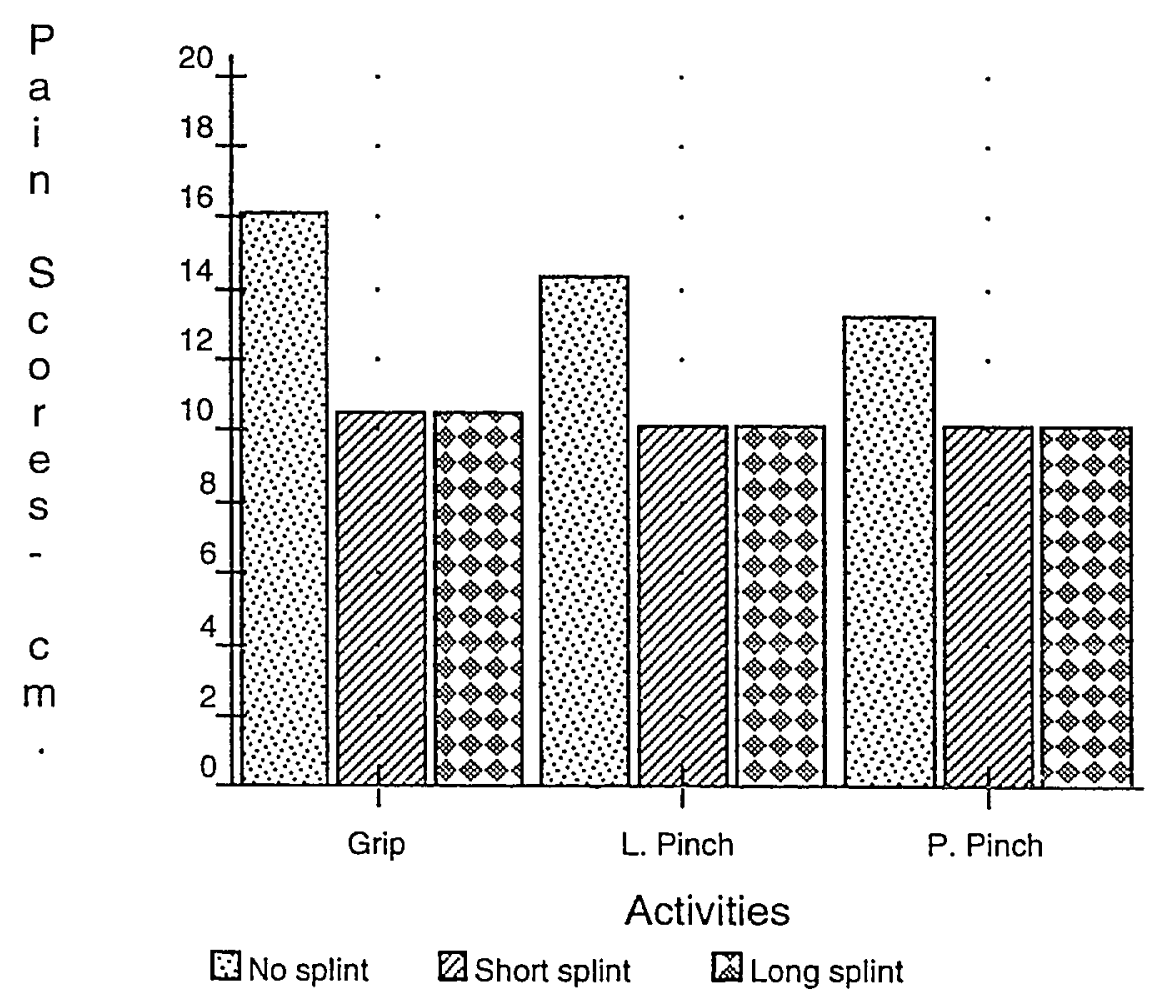

Figure 26. Cumulative Pain Scores in Grip and Pinch Testing 
Relationship of Cumulative Pain Scores in CMC Activities for the Three Conditions of Splinting

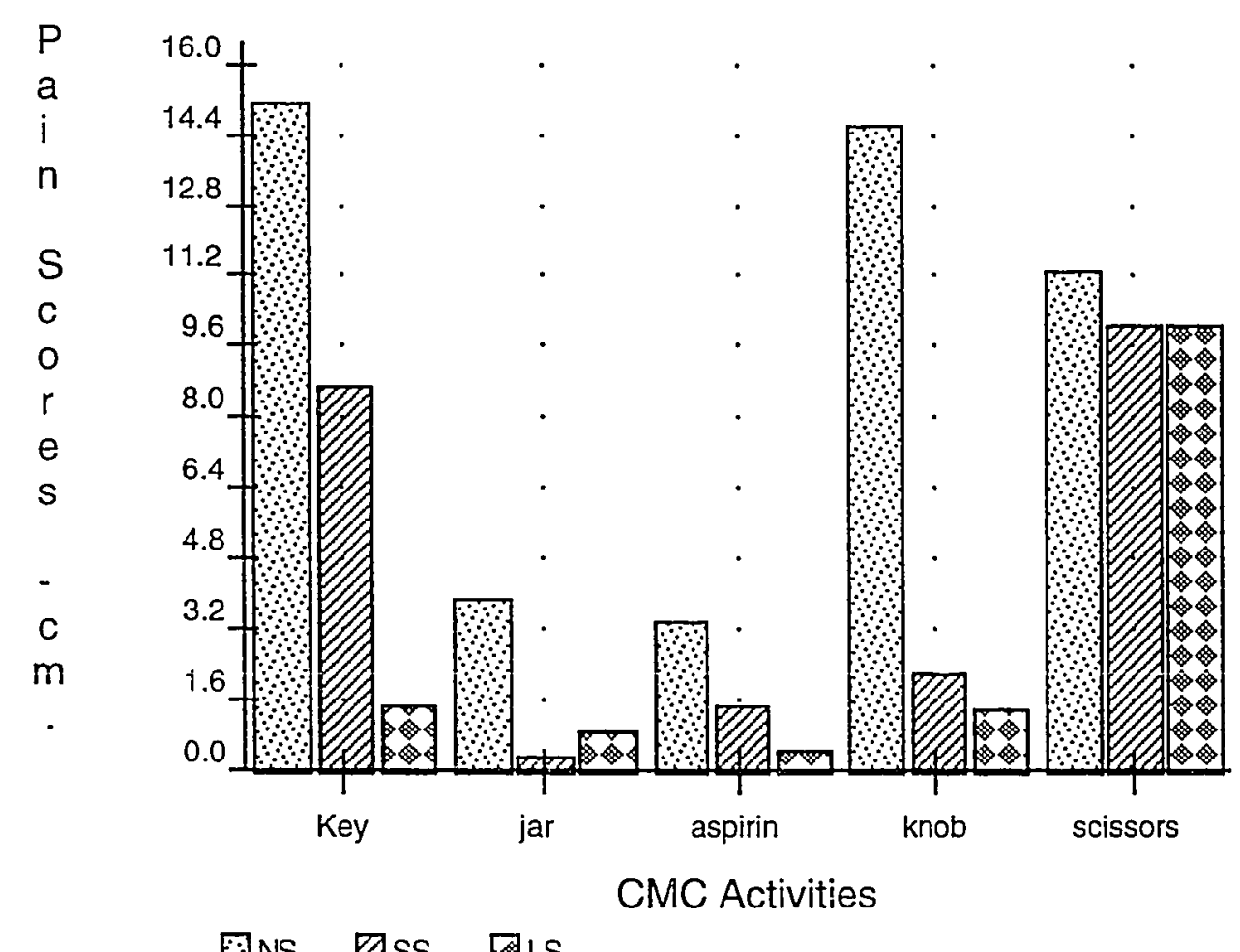

Fiqure 27. Cumulative Pain Scores in CMC Activities 
Relationship of Cumulative Pain Score in the Jebsen Hand Function Test for the Three Conditions of Splinting

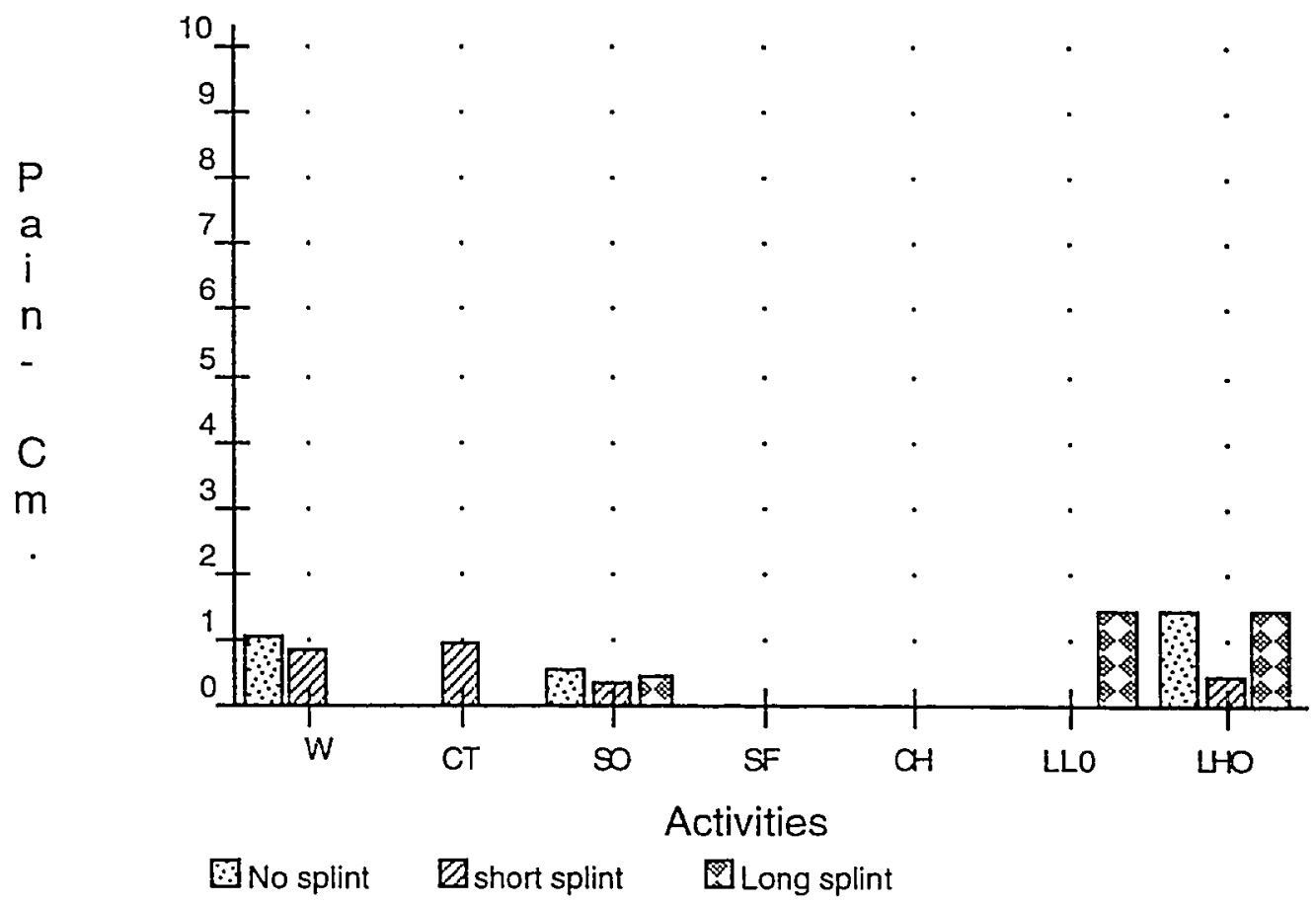

Figure 28. Cumulative Pain Scores in the Jebsen Hand Function Test (Jebsen,1969) 


\section{CHAPTER 5}

\section{DISCUSSION \\ PROFESSIONAL IMPLICATIONS}

The purpose of the study was to determine the effectiveness of two types of splints, the short hand-based thumb splint and the long wrist thumb splint and to determine the effectiveness of the splinting on pain and hand function as compared to no splinting.

Outcome studies of therapeutic modalities are becoming increasingly important in rehabilitation. Increased scrutiny of health care professionals and services occurs. The need for accountability affects payment for services and even the maintenance of occupational therapy services. Research on outcomes contributes to the body of knowledge in the field of occupational therapy.

In the treatment of thumb $\mathrm{CMC}$ arthritis, it is assumed that increased function and pain relief will be the outcome of splinting the CMC joint. The results of this study indicate that splinting, either short or long will provide pain relief and maintain function. The short hand-based splint is adequate. Clinically, the short splint is less confining, and patients usually comply with its use. The short splint is adequate for the diagnosis of $\mathrm{CMC}$ arthritis during the earlier stages of the disease process, but this may not apply to all cases.

In the framework of occupational performance, the performance component of sensory and motor have been scrutinized with stage one: adjunctive methods. Although splinting is a basic level stage of the treatment continuum, the outcome of splinting affects the higher occupational performance levels of self care, work, play and life space (Pedretti \& Pasquinelii, 1990). The result of the study is that hand function or performance were not significantly affected. The inference might be that these splints do not prevent the normal hand function that is needed for daily activities. Splinting is an adjunctive modality that allows individuals to get on with their lives and perform 
activities for employment as well as leisure activities. In patients with CMC arthritis, adjunctive methods of treatment allow a person to progress to stage four activities quickly. The sensory pain component of motor function was measured separately from function in the study, but these factors are inseparable in performance. When pain is increased and decreased, the significant difference in the motor performance component may be difficult to measure. This is often true with patients that clinicians feel are malingering or "faking it."

Within the parameters of hand motor function there are many factors. This research addressed simple motor performance problems with no neurological complications. Two components encountered in the motor performance component of this study were time and strength. In this study, time seems to be less of a factor in thumb dysfunction and pain than strength, although this study did not address the use of the CMC joint over time, as in cumulative trauma disorders. The subjects already had CMC damage due to age and overuse.

All subjects had pain with grip and lateral pinch. The literature review on biomechanics of the thumb indicated that the dislocating force at the thumb is thumb adduction, as in lateral pinch, while the abductor pollicis longus exerts a force on the first metacarpal to pull it off the trapezium. Tasks that require sustained pinch or that create some resistance for lateral pinch will create pain and a chance of dislocation. The CMC activities which had high pain scores and utilized lateral pinch motions were: using a key and using scissors. Although the pads of the thumb and finger do not meet in the use of the scissors, there are alternating movements of adduction and abduction at the CMC joint. The movement of the scissors produces a dynamic, alternating resistive force rather than a static resistive force on the $\mathrm{CMC}$ joint and may account for the increase in perceived pain.

In the study by Cooney and Chao (1977) joint compression forces of 12 kilograms 
exists at the CMC joint for every 1 kilogram of applied force on the thumb. In Subject D the dynamometer created enough force into the web space that even splinting and positioning did not help.

Splinting of the wrist does not appear to make much difference in the level of function. Function was maintained. Some activities are more efficient with the use of the short splint, however, with practice the long splint may do just as well if pain is severe.

\section{DISCUSSION}

Since this is a 5 person case study, there is much room for speculation about the subjects, degree of CMC arthritis, and methodology. Factors that were not considered were types of medication subjects were taking and when they were taken. Several patients had multiple medical problems and medications were not controlled. However, four out of five patients were not taking anti-inflammatory medication at the time of the study. Another consideration of the study is the effect that practice and repetition of an activity would have on the results. However, in this study the conditions for each trial also changed.

This study identified that functional tasks are valuable in challenging and testing the CMC joint. Occupational therapists are able to glean valuable information from informal evaluations during activities of daily living assessments. Being able to identify tasks that are prone to create pain and dysfunction informally has its value when there is a question of faking disability. Tasks that challenge the CMC joint are activities that are necessary for entering or leaving a room or building (using a key, turning a door knob), or opening or closing a container (opening an aspirin bottle, or jar).

Although the Jebsen Hand Function Test (Jebsen, 1969) does not generate pain in the performance of the activities, the cumulative effects of fine motor activities over time are difficult to measure. Activities that have a cumulative effect on the thumb are 
writing, picking up small objects, checkers and turning cards. Studies on repetitive motion and fine motor skills would be interesting research.

By conducting the study, it became apparent that the tasks used in the test could be used to test the splints for comfort and fit. The tests were quick and items were always easily accessible: a door, a key. a bottle, and a pair of scissors.

\section{RECOMMENDATIONS}

In CMC arthritis, the stability of the injured joint is easily challenged by activity. It is the position of the thumb and force or resistance to the thumb in an activity that creates pain and discomfort. If this study was to be continued or expanded, it is recommended that the Jebsen Hand function Test (Jebsen, 1969) be discontinued, and tests of grip, lateral pinch, palmar pinch be maintained. A quick test for $\mathrm{CMC}$ arthritis using the CMC Activity Test could be initiated. The other recommendation would be to design a simpler research project with more subjects. CMC arthritis occurs frequenily in the general population. The order of the splints could be changed or different splints could be used. This study explored the motor and sensory components of hand function with the occupational therapy adjunctive modality of splinting with interesting results and implications for further research. Further research into the components of fine motor and gross motor function of hand function and pain in performance might also be explored as well as the cumulative effects of these activities.

\section{SUMMARY}

This study involved 5 case studies of men and women who were diagnosed with carpometacarpal arthritis and referred to hand therapy for splinting. The purpose of the study was to examine two types of splints used for CMC arthritis, the short handbased splint and the long thumb, wrist splint and determine the effectiveness of splinting on hand function and pain as compared to the unsplinted hand. The subjects participated in a series of motor performance activities, the Jebsen Hand Function Test (Jebsen, 
1969) grip, pinch strength and a series of activities that tend to challenge the CMC

joint. Subjectively, subjects were happy with their splints and some patients had better pain relief than others.

The results of the study indicated that the pain relief by the short and long splint were equal but that functional performance did not make a difference. However, if the arthritic degenerative disease process is in the beginning stages, and there are no other complications of the thumb and wrist, a short splint is adequate. The long splint in this study is created with a combination of the short, custom made hand based splint and a prefabricated wrist splint. In reality, the long wrist splint is given to the patient and offers the patient the option of both splints. Further studies on splinting and related topics are recommended. 
REFERENCES

American Medical Association (1958). Guide to the evaluation of permanent impairment of the extremities and back (Special edition). The American Journal of American Medical Association.

American Society of Hand Therapists. (1992). Clinical assessment recommendations (2nd. ed.). Publication of the American Society of Hand Therapists. U.S.A.

Agur, A. M. (1991). Grant's Atlas of Anatomy (2nd edition). Baltimore: Williams and Wilkins.

Aulicino P. L., \& DuPuy T. E. (1984). Clinical examination of the hand. In Hunter, J. M., Schneider, L. H., Mackin, E. J., \& Callahan A., D. (Eds.), Rehabilitation of the Hand (pp. 25-48). St. Louis: C. V. Mosby.

Bradley K. A., Anderson K. O., Young L. D., \& Williams T. (1989). Psychological testing. In D. C. Tollison (Ed.), Handbook of chronic pain management (pp. 570-591). Baltimore: Williams and Wilkins.

Brand, P. W., \& Hollister, A. (1993). Clinical Biomechanics of the Hand (2nd edition). St. Louis: Mosby Year Book, Inc..

Burton, R. I. (1986). Basal joint arthritis, Orthopedic Clinics of North America, 17 (3), 493-503.

Brunelli, G., Monini L., \& Brunelli, F. (1989). Stabilisation of the trapezimetacarpal joint. Journal of Hand Surgery, 14-B (2), 209-212.

Christiansen, C., \& Baum C. (1991). Occupational Therapy, overcoming human performance deficits. Thorofare, SLACK, Inc.

Cooney, W. P., \& Chao, E. Y. (1977). Biomechanical analysis of static forces in the thumb during hand function. The Journal of Bone and Joint Surgery, 59-A (1), 27-36. 
Cooney, W. P., Lucca, M. J., Chao, E. Y., \& Lincsheid, R. L. (1981). The kinesiology of the thumb trapeziometacarpal joint. Journal of Bone and Joint Surgery, 63-A (9), $1371-1381$

Eaton, R. G., Lane L. B., Littler, J. W. , \& Keyser, J., J. (1984). Ligament reconstruction for the painful thumb carpometacarpal joint: A long term assessment. Journal of Hand Surgery, 9 A (8), 692-699.

Fess, E. E., \& Philips, C. A. (1987). Hand splinting: Principles and methods (2nd ed.). St. Louis: C. V. Mosby.

Flatt, A. E. (1983). Care of the arthritic hand (4th ed.). St. Louis: C. V. Mosby. Flatt, A. E. (1979). The care of minor hand injuries (4th ed.). St. Louis: C. V. Mosby. Fries, J. F. (1988). Arthritis (5th ed.). New York: Addison-Wesley.

Hopkins, H. L. (1988). Current basis for the theory and philosophy of occupational therapy. Occupational Therapy. Philadelphia: Lippincott.

Imaeda, T., An, K. , \& Cooney, W. P. (1992). Functional anatomy and biomechanics of the thumb. Hand Clinics, $\underline{8}(1), 9-15$.

Jebsen, R. H., Taylor N., Trieschman, R. B., Trotter, M. S., \& Howard, L. A. (1969). An objective and standardized test of hand function. Archives of Physical Medicine and Rehabilitation, $\underline{50}, 311-319$.

Melvin, J. L. (1982). Rheumatic disease: Occupational therapy and rehabilitation (2nd ed.). Philadelphia: F. A. Davis.

Napier, J. R. (1955). The form and function of the carpometacarpal joint of the thumb. Journal of Anatomy, $\underline{83}(3), \quad 362-369$.

Oyster, C. K., Hanten, W. P., \& Llorens L. A. (1987). Introduction to research. New York: J. B. Lippincott.

Pedretti, L. W., \& Pasquinelli, S. (1990). Foundation for treatment of physical dysfunction. In Pedretti \& Zolton, Occupational therapy: Practice skills for physical 
dysfunction (3rd ed., pp. 1-17). St. Louis: C. V. Mosby.

Reed, K. L. (1984). Models of practice in occupational therapy. Philadelphia: Williams and Wilkins.

Reed, K. L. (1991). Concepts of Occupational Therapy. Philadelphia: Williams and Wilkins.

Smith, R. O., \& Benge, M. W. (1985). Pinch and grasp strength: Standardization of terminology. American Journal of Occupational Therapy, 39 (8), 531-535.

Swanson, A. B. (1964). Evaluation of impairment of function in the hand. Surgical Clinics of North America, 44 (4), 925-940. 
APPENDIX A

SAN JOSE STATE UNIVERSITY HUMAN SUBJECTS CONSENT FORM 


\author{
AGREEMENT TO PARTICIPATE IN RESEARCH \\ SAN JOSE STATE UNIVERSITY \\ RESPONSIBLE INVESTIGATOR: YURIKO WONG, OTR, CHT \\ TITLE OF PROTOCOL: A COMPARATIVE STUDY ON SPLINTING, HAND FUNCTION, AND PAIN \\ IN CARPOMETACARPAL ARTHRITIS
}

\author{
Informed Consent
}

I have been asked to participate in a research study that is investigating the benefits of two types of splinting methods used with arthritis of the thumb in activities that are performed in daily activities and during a standard hand evaluation. The results of the study should further our understanding of which splint helps reduce pain and stabilizes the thumb during everyday activities.

I understand that

1. I will be asked to participate in a normal hand evaluation of grip and pinch test, participate in certain daily activities such as writing, picking up small objects, lifting a 1 pound grocery store can, using a key to open a door, and opening a jar. I will be tested without the use of the splints and will be asked to rate the amount of pain on a scale of 0 (no pain) to 10 (severe pain). I will wear a small plastic, removable thumb splint constructed as standard treatment for my thumb and tested again. In the third test a long wrist splint is placed over the first splint and the test is repeated. This may take 2 or 3 sessions of ninety minutes each.

2. The possible risks of this study are minimal. The discomfort I will feel or injury that can occur is the same as when I am using my thumb and hand during therapy.

3. The possible benefits of the study to me are that I would understand the reason for the use of the splints and understand which splint would provide better pain relief as 1 perform certain activities.

4. I understand that these are standard treatment procedures. 
5. The results from this may be published, but any information from this study that can be identified with me will remain confidential and will be disclosed only with my permission or as required by law.

6. I understand that there is no compensation for this study.

7. Any question about my participation in this study will be answered by Yuriko Wong, (415) 493-5000 x-5936. Complaints about the procedure may be presented to Gordon Burton, Ph.D. (408) 924-3070. For questions or complaints about research subject's rights or in the event of research related injury, contact Serena Stanford, Ph. D. (Associate Academic Vice President for Graduate Studies \& Research) at (408) 924-2480.

8. My consent is given voluntarily without being coerced; I may refuse to participate in this study or in any part of this study, and I may withdraw at any time, without prejudice to my relations with San Jose State University and the Palo Alto Veterans Affairs Medical Center.

9. I have received a copy of this consent form for my file.

I HAVE MADE A DECISION WHETHER OR NOT TO PARTICIPATE. MY SIGNATURE INDICATES THAT I HAVE READ THIS INFORMATION PROVIDED ABOVE AND THAT I HAVE DECIDED TO PARTICIPATE

DATE
SUBJECTS SIGNATURE

INVESTIGATOR'S SIGNATURE 
APPENDIX B

CARPOMETACARPAL DATA SHEET

CASEA 


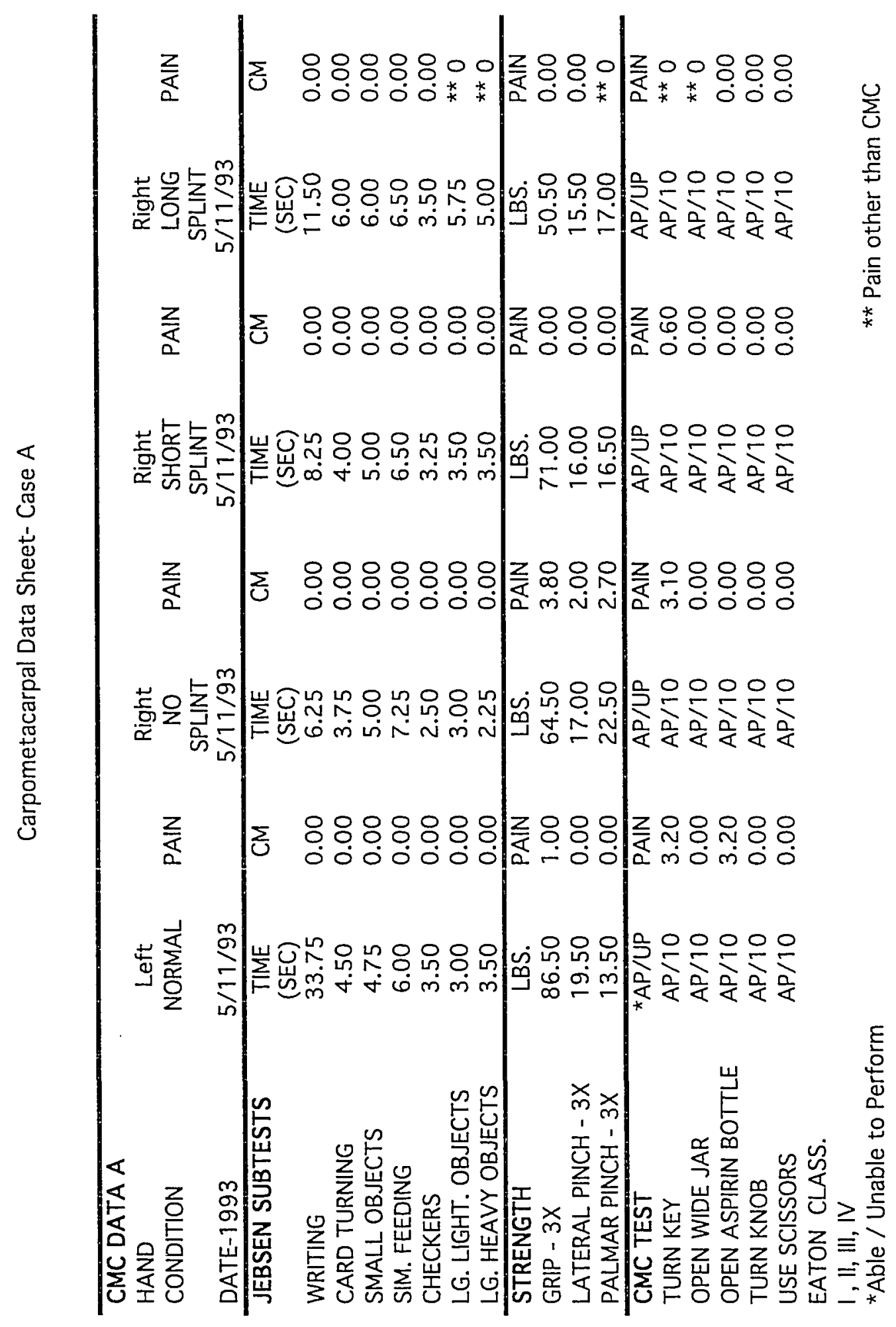


APPENDIXC

JEBSEN MEANS AND STANDARD DEVIATION 
JEBSEN MEAN AND STANDARD DEVIATIONS

FOR NORMAL SUBJECTS

DOMINANT HAND

\section{FACTOR}

\begin{tabular}{|c|c|c|c|c|}
\hline ACE & $20-59$ & $60-94$ & $20-59$ & $60-94$ \\
\hline writing & $12.2 \pm(3.5)$ & $19.5 \pm(7.5)$ & $11.7 \pm(2.1)$ & $15.7 \pm(4.7)$ \\
\hline cards & $4.0 \pm(0.9)$ & $5.3 \pm(1.6)$ & $4.3 \pm(1.4)$ & $4.9 \pm(1.2)$ \\
\hline small objects & $5.9 \pm(1.0)$ & $6.8 \pm(1.2)$ & $5.5 \pm(0.8)$ & $6.6 \pm(1.3)$ \\
\hline feeding & $6.4 \pm(0.9)$ & $6.9 \pm(0.9)$ & $6.7 \pm(1.1)$ & $6.8 \pm(1.1)$ \\
\hline checkers & $3.3 \pm(0.7)$ & $3.8 \pm(0.7)$ & $3.3 \pm(0.6)$ & $3.6 \pm(0.6)$ \\
\hline light objects & $3.0 \pm(0.4)$ & $3.6 \pm(0.7)$ & $3.1 \pm(0.5)$ & $3.5 \pm(0.6)$ \\
\hline heavy objects & $3.0 \pm(0.5)$ & $3.5 \pm(0.7)$ & $3.2 \pm(0.5)$ & $3.5 \pm(0.6)$ \\
\hline NONDOMINANT HAND & \multicolumn{2}{|c|}{ MALES } & \multicolumn{2}{|c|}{ FEMALES } \\
\hline$A G E$ & $20-59$ & $60-94$ & $20-59$ & $60-94$ \\
\hline writing & $32.3 \pm(11.8)$ & $48.2 \pm(19.1)$ & $30.2 \pm(8.6)$ & $38.9 \pm(14.9)$ \\
\hline cards & $4.5 \pm(0.9)$ & $6.1 \pm(2.2)$ & $4.8 \pm(1.1)$ & $5.5 \pm(1.1)$ \\
\hline small objects & $6.2 \pm(0.9)$ & $7.9 \pm(1.9)$ & $6.0 \pm(1.0)$ & $6.6 \pm(0.8)$ \\
\hline feeding & $7.9 \pm(1.3)$ & $8.6 \pm(1.5)$ & $8.0 \pm(1.6)$ & $8.7 \pm(2.0)$ \\
\hline checkers & $3.8 \pm(0.6)$ & $4.6 \pm(1.0)$ & $3.8 \pm(0.7)$ & $4.4 \pm(1.0)$ \\
\hline light objects & $3.2 \pm(0.6)$ & $3.9 \pm(0.7)$ & $3.3 \pm(0.6)$ & $3.4 \pm(0.6)$ \\
\hline heavy objects & $3.1 \pm(0.4)$ & $3.8 \pm(0.7)$ & $3.3 \pm(0.5)$ & $3.7 \pm(0.7)$ \\
\hline
\end{tabular}

FEMALES 
APPENDIX D

CARPOMETACARPALDATA SHEET

CASEB 


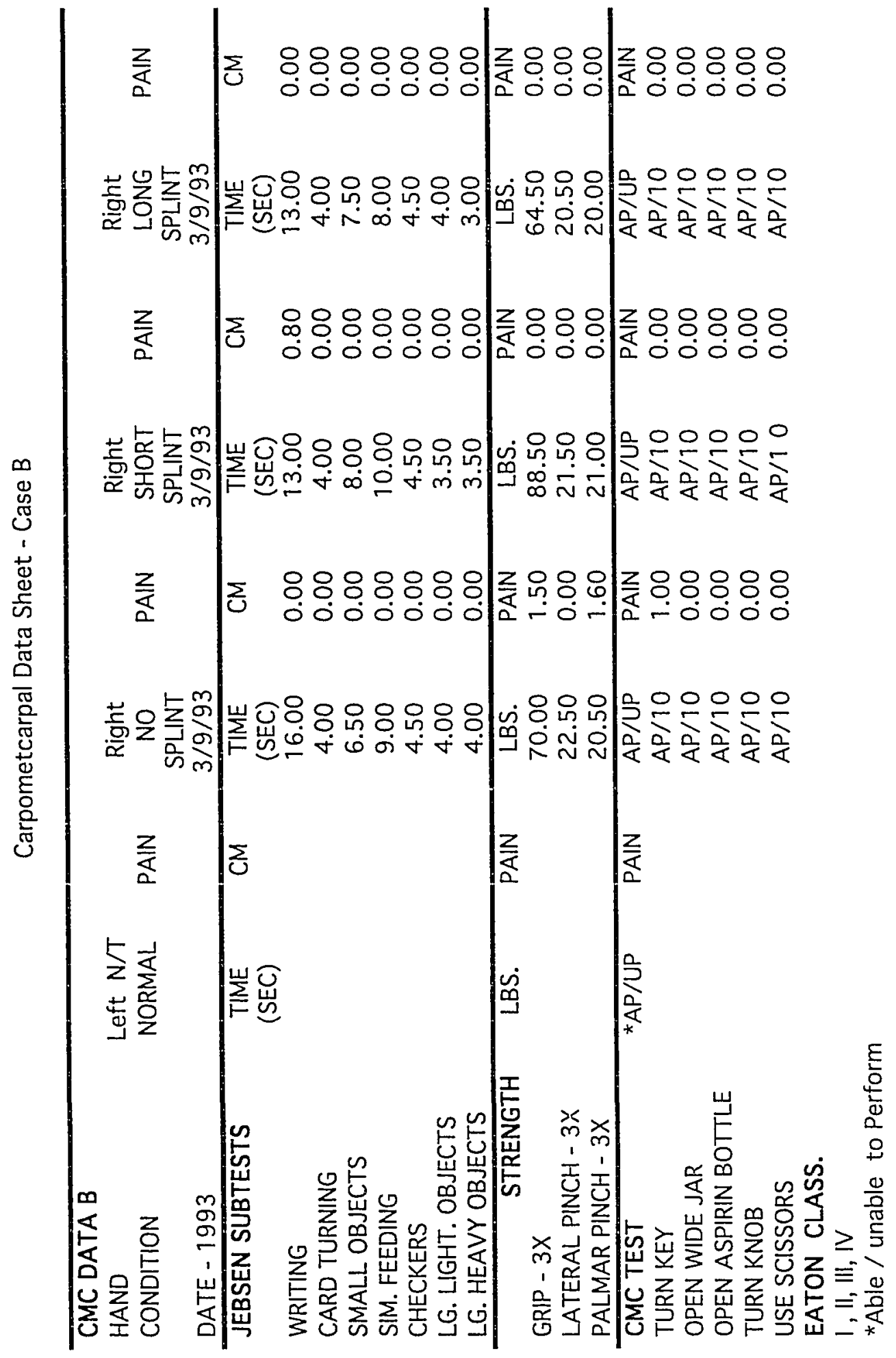


APPENDIXE

\section{CARPOMETACARPAL DATA SHEET}

CASEC 


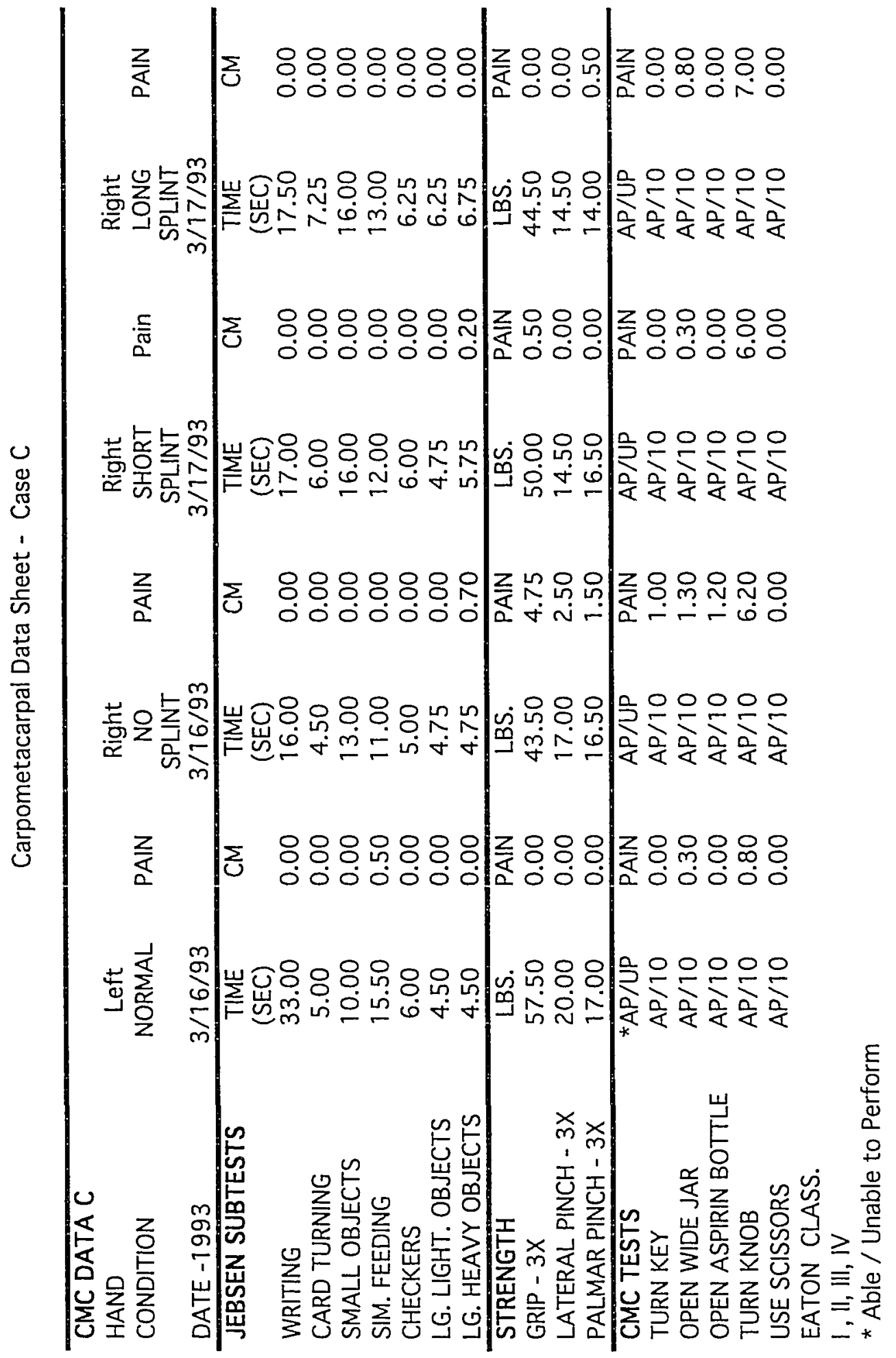


APPENDIX F

CARPOMETACARPAL DATA SHEET

CASED 


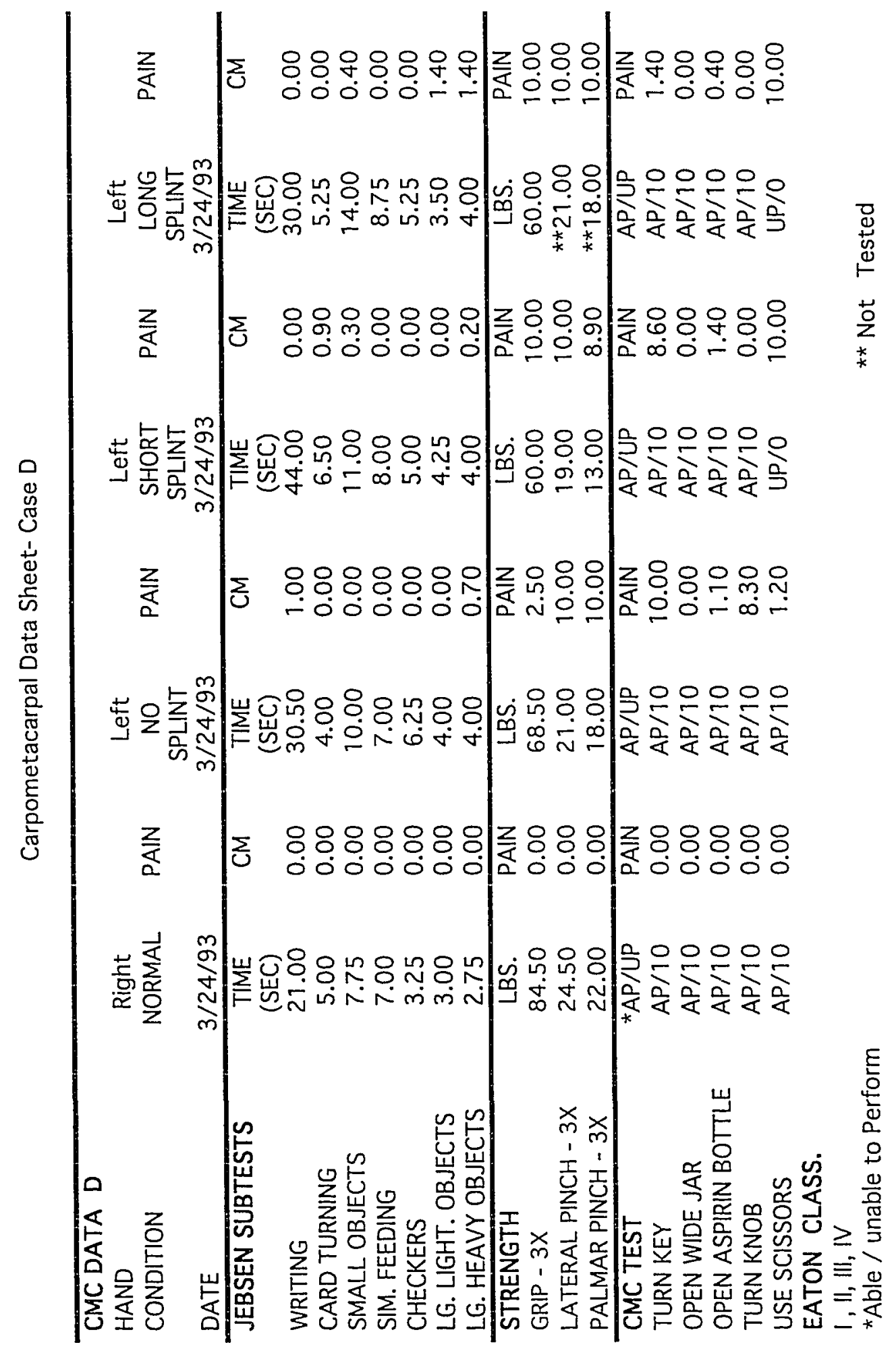


APPENDIX G

CARPOMETACARPALDATA SHEE!

CASEE 


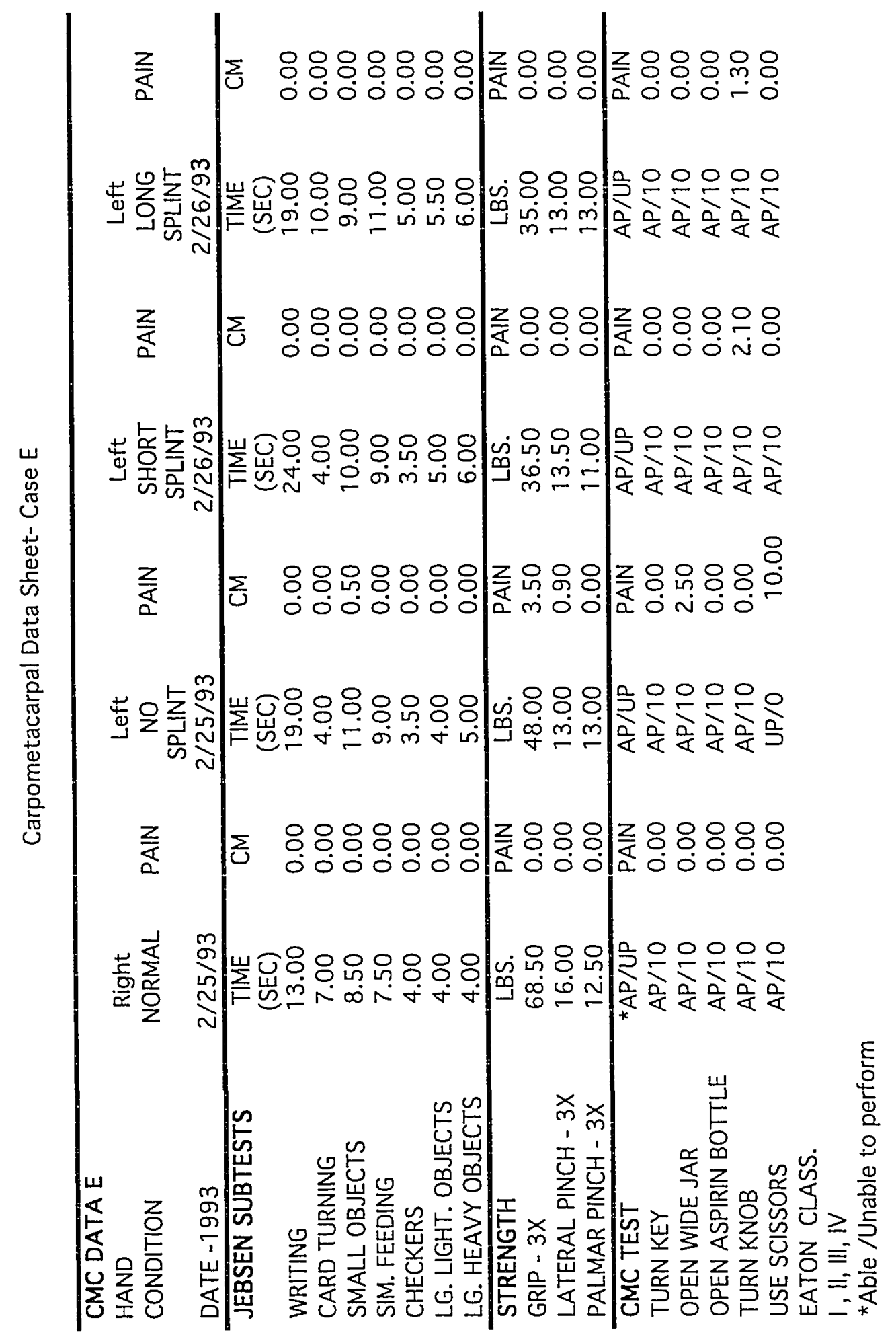

